Article

\title{
Sea Surface Temperature Retrieval from the First Korean Geostationary Satellite COMS Data: Validation and Error Assessment
}

\author{
Hye-Jin Woo ${ }^{1}$, Kyung-Ae Park ${ }^{2, *}$, Xiaofeng Li $^{3}(\mathbb{D})$ and Eun-Young Lee ${ }^{1}$ \\ 1 Department of Science Education, Seoul National University, Seoul 08826, Korea; \\ hyejinwoo@snu.ac.kr (H.-J.W.); eunyounglee@snu.ac.kr (E.-Y.L.) \\ 2 Department of Earth Science Education/Research Institute of Oceanography, Seoul National University, \\ Seoul 08826, Korea \\ 3 Global Science and Technology, National Oceanic and Atmospheric Administration (NOAA)-National \\ Environmental Satellite, Data, and Information Service (NESDIS), College Park, MD 20740, USA; \\ xiaofeng.li@noaa.gov \\ * Correspondence: kapark@snu.ac.kr; Tel.: +82-2-880-7780
}

Received: 24 October 2018; Accepted: 28 November 2018; Published: 30 November 2018

\begin{abstract}
Korea's first geostationary satellite, the "Communication, Ocean, and Meteorological Satellite" (COMS), has been operating since 2010. The Meteorological Imager (MI), an sensor on-board the COMS, has observed sea-surface radiances for the estimation of sea surface temperature (SST) in the western Pacific Ocean and eastern Indian Ocean. To derive the SST coefficients of COMS, quality-controlled surface drifting buoy data were collected for the period of April 2011 to March 2015. A collocation procedure between COMS/MI data and the surface drifter data produced a matchup database for 4 years from 2011 to 2015. The coefficients for the COMS/MI SST were derived by applying appropriate algorithms, i.e., the Multi-channel SST (MCSST) and Non-linear SST (NLSST) algorithms, for daytime and nighttime data using a regression method. Validation results suggest the possibility of the continuous use of the coefficients as representative SST coefficients of COMS. The estimated SSTs near the edge of a full disk with high satellite zenith angles over $60^{\circ}$ revealed relatively large errors compared to drifter temperatures. Most of NLSST formulations exhibited overestimation of SSTs at low SSTs $\left(<10^{\circ} \mathrm{C}\right)$. This study suggests an approach by which SST can be measured accurately in order to contribute to tracking climate change.
\end{abstract}

Keywords: sea surface temperature (SST); COMS/MI; MCSST; NLSST; SST coefficients

\section{Introduction}

Sea surface temperature (SST) is one of the most important variables to understand oceanic and atmospheric phenomena, such as current fronts [1] and west boundary currents [2], air-sea interaction [3,4], and climate change [5,6]. Global SSTs derived from satellite-measured radiance have been used for weather forecasting and climate prediction applications. Infrared sensors onboard near-polar orbiting satellites and geostationary satellites can provide global SST fields at relatively high spatial (polar orbiting) and temporal (geostationary) resolution, which makes possible the frequent tracking of the ocean phenomena and their diurnal variations under clear sky conditions. Geostationary satellites, such as the Geostationary Operational Environmental Satellites (GOES) of the National Oceanic and Atmospheric Administration (NOAA), and the Meteosat Second Generation (MSG) of European Organization for the Exploitation of Meteorological Satellites (EUMETSAT), a series of Himawari of Japan Meteorological Agency (JMA), have shown the capacity for accurate monitoring of high-temporal SST images for oceanic research and operations [7-9]. 
Since Anding and Kauth [10] and Prabhakara et al. [11] proposed an algorithm in the early 1970's for SST retrieval using brightness temperatures (BTs) observed by satellite, several studies on the development of SST algorithms has emerged. Multichannel SST (MCSST) [12-15] and Nonlinear SST (NLSST) [16-19] algorithms, which are used for most operational SST retrieval [7,20], are representative empirical regression algorithms. A variety of algorithms based on MCSST and NLSST were evaluated and adapted as more accurate methods for SST [21,22]. In addition, as the available channels for SST retrieval are increased, the SST fields have been derived by applying an empirical regression algorithm optimized for each sensor [23]. The regression methods of MCSST and NLSST are still widely used for near-polar orbiting satellites as well as geostationary satellites [20-23]. As the real-time simulated BTs data from radiative transfer model (RTM) $[24,25]$ using numerical weather prediction (NWP) model fields are available, the physical algorithms, such as the stochastic [26,27] or deterministic method [28], have been also developed for operational SST retrieval.

The first geostationary satellite of Korea, the "Communication, Ocean and Meteorological Satellite" (COMS) of the Korean Meteorological Administration (KMA), was launched on 27 June 2010 and is located at $128.2^{\circ}$ E over the equator, covering the western Pacific Ocean and its marginal seas including the East China Sea, the Yellow Sea, the East Sea (called Sea of Japan), and the South China Sea, as well a part of the eastern Indian Ocean (Figure 1). Figure 1a shows the bathymetry obtained from ETOPO5 database from National Geophysical Data Center (NGDC) of NOAA (https: / / www.ngdc.noaa.gov). The Meteorological Imager (MI) of the COMS has been operationally utilized since 2010. The area covered by COMS/MI is one of the most important regions, because it includes a warm pool of the tropical Indian Ocean and western Pacific Ocean, and the Kuroshio Current as one of the largest western boundary currents. The warm pool, which is characterized by the warmest SSTs, i.e., over the about $28^{\circ} \mathrm{C}$, and with the most active atmospheric convection, has a strong influence on climate change [29]. The Kuroshio Current has played an important role in global ocean circulation, transporting a large amount of heat from the tropical ocean to the mid latitudes [30]. For this reason, several countries in the Asia-Pacific region have received the COMS/MI data and used them for diverse oceanic and atmospheric purposes.
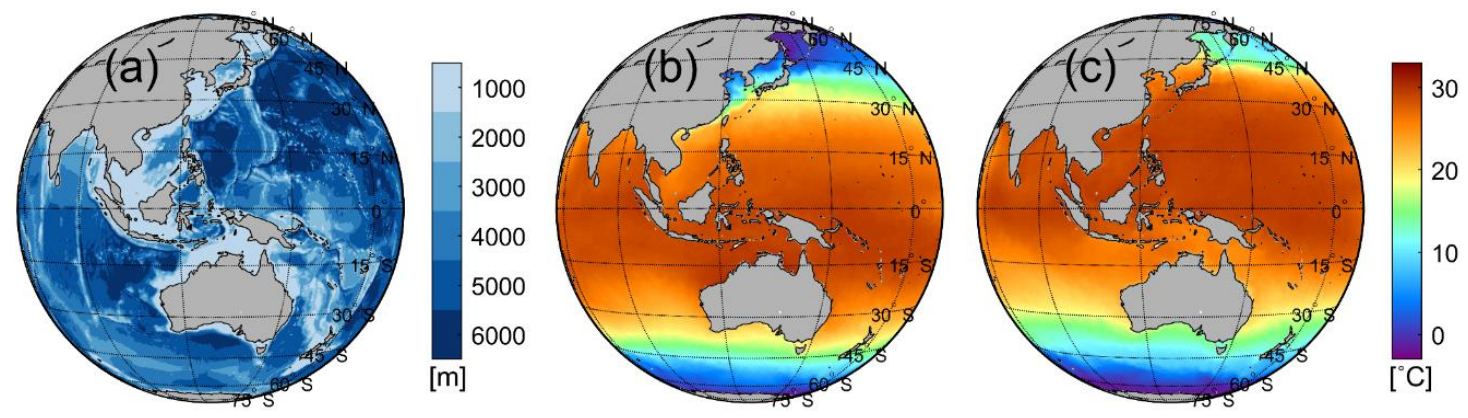

Figure 1. (a) Bathymetry and the sea surface temperature climatology in the COMS/MI full-disk area in (b) February and (c) August.

Despite the importance of SST data in this region, COMS/MI-observed SSTs have been limited used so far. Considering the 8-year database of COMS data, it is anticipated that a COMS/MI-derived SST database could contribute to the production of continuous time series of SST in this particular region. Therefore, in order to understand ocean phenomena using COMS/MI SST data and to improve predictions of SSTs in the western Pacific Ocean, it is necessary to derive SST retrieval coefficients.

In response to this necessity, the main objective of this study is to provide SST coefficients for COMS data. The more detailed objectives are (1) to produce a matchup database between COMS satellite data and in situ measurements, (2) to remove cloudy and cloud-contaminated pixels from the regression procedure, (3) to compare the estimated SSTs in this study with the SST retrievals using previously-known algorithms, (4) to present the coefficients of MCSST and NLSST for COMS data, 
(5) to understand and discuss the characteristics of SST errors, especially in the seas around Korea, and (6) to validate the satellite SST retrievals using the drifting buoy measurements.

\section{Data}

\subsection{Satellite Data}

COMS/MI has one channel in the visible spectrum (VIS, $0.55 \mu \mathrm{m}-0.80 \mu \mathrm{m}$ ) and four infrared-sensing channels (shortwave (SWIR); $3.5 \mu \mathrm{m}-4.0 \mu \mathrm{m}$, water vapor (WV); $6.5 \mu \mathrm{m}-7.0 \mu \mathrm{m}$, infrared1 (IR1); $10.3 \mu \mathrm{m}-11.3 \mu \mathrm{m}$, and infrared2 (IR2); $11.5 \mu \mathrm{m}-12.5 \mu \mathrm{m}$ ). The spatial resolution of MI is $1 \mathrm{~km} \times 1 \mathrm{~km}$ in the visible channel and $4 \mathrm{~km} \times 4 \mathrm{~km}$ in the infrared channels at the nadir (Table 1 ). The COMS/MI provides visible and thermal IR radiance data at the top of the atmosphere every $3 \mathrm{~h}$ for the full disk and every $15 \mathrm{~min}$ for the regional area including the Korean Peninsula. We used the full-disk L1B data of COMS/MI from April 2011 to March 2015 to estimate the coefficients for SST retrieval and validate the calculated SST. These data were obtained from the Satellite Earth-Ocean science \& edUcation Lab (SEOUL) of Seoul National University (SNU) and the National Meteorological satellite Center (NMSC) of KMA.

Table 1. Spectral channel characteristics of the Meteorological Imager (MI) on Communication, Ocean and Meteorological Satellite (COMS) (VIS: visible, SWIR: shortwave infrared, WV: water vapor, IR1: infrared 1, IR2: infrared 2).

\begin{tabular}{cccccc}
\hline Channel & Description & Wavelength $(\mu \mathrm{m})$ & Bandwidth $(\mu \mathrm{m})$ & NEDT at 300K $(\mathbf{K})$ & Spatial Resolution $(\mathbf{k m})$ \\
\hline 1 & VIS & 0.675 & $0.55-0.80$ & & 1 \\
2 & SWIR & 3.75 & $3.5-4.0$ & $<0.10$ & 4 \\
3 & WV & 6.75 & $6.5-7.0$ & $<0.12$ & 4 \\
4 & IR1 & 10.8 & $10.3-11.3$ & $<0.12$ & 4 \\
5 & IR2 & 12.0 & $11.5-12.5$ & $<0.20$ & 4 \\
\hline
\end{tabular}

NMSC/KMA performed COMS/MI infrared sensor calibration against the Infrared Atmospheric Sounding Interferometer (IASI) on board the Meteorology Operational Satellite-A (MetOp-A) [31] under the Global Space-based Inter-Calibration System (GSICS) [32] program. The correction coefficients of MI radiance data have been distributed through the NMSC website [33]. When comparing the BT between MI and IASI, the IR1 and IR2 channels used for SST calculation showed a positive bias of about $1{ }^{\circ} \mathrm{C}$ near $200 \mathrm{~K}$ in extreme cases; however, it was small and stable at a warm range of $-25^{\circ} \mathrm{C}$ with negligible biases such as $0.76 \mathrm{~K}, 0.34 \mathrm{~K}, 0.03 \mathrm{~K}$ at BT values of $220 \mathrm{~K}, 250 \mathrm{~K}$, and $290 \mathrm{~K}$, respectively [31]. Since the calculation range of SST is between $-5^{\circ} \mathrm{C}-35^{\circ} \mathrm{C}$, no additional correction of radiance measurements was performed in this study.

\subsection{In Situ Temperature Measurements}

We collected the SST measurements obtained by drifting and moored buoys. These data are distributed through the Global Telecommunication System (GTS) of the World Meteorological Organization (WMO), and are operationally archived by KMA. The majority of drifting buoys measure the subsurface temperature at about 20-cm depth [34], while moored buoys measure at depths of a few tens of centimeters to a few meters, depending on the type of buoy and deployment location. We used only drifting buoy SSTs for estimating the SST coefficients and validation of retrieved SSTs.

Since in situ SST measurements obtained through GTS are occasionally suboptimal with unexpected values, quality control $(\mathrm{QC})$ procedures are essential for the calibration and validation of satellite-derived SSTs [35]. In this study, a series of QC procedures developed by the KMA were applied to the individual buoy data in an effort to eliminate low-quality measurements and minimize the errors in the following process. The QC procedure was performed separately for each buoy. To begin with, if the number of observations within a day was less than 10, or the maximum difference of temperatures within a day is equal to $0{ }^{\circ} \mathrm{C}$ or greater than $4{ }^{\circ} \mathrm{C}$ due to malfunctioning of the 
drifters, then the data were discarded. Next, the time-continuity test was performed by removing the data that is three standard deviations larger than the daily mean. For rigorous QC of the buoy data, the time-continuity test was repeated over 4 days of data collection. Finally, if the standard deviation of the data over 4 days was equal to zero or greater than $2{ }^{\circ} \mathrm{C}$, all data for that period were eliminated. These QC procedures could significantly reduce errors in buoy measurements. The uncertainty of quality-controlled buoy SSTs estimated using the three-way error analysis between the Advanced Along Track Scanning Radiometer (AATSR), the Advanced Microwave Scanning Radiometer-EOS (AMSR-E), and buoys, was $0.23^{\circ} \mathrm{C}$ [36].

Figure 2 shows a comparison of time-series drifter temperatures before and after the quality-control procedures. The temporal change of the original drifter temperatures (Figure 2a,c) shows intermittent displacement with unusual spikes beyond the average water temperature range before the QC procedure. However, these abnormal data have been completely eliminated through the QC process, as shown in Figure $2 b$, $d$ and eventually follow the overall pattern of time variations of SST. After evaluating the quality of the drifter temperature for 4 years, $15.4 \%$ of the total data were removed.
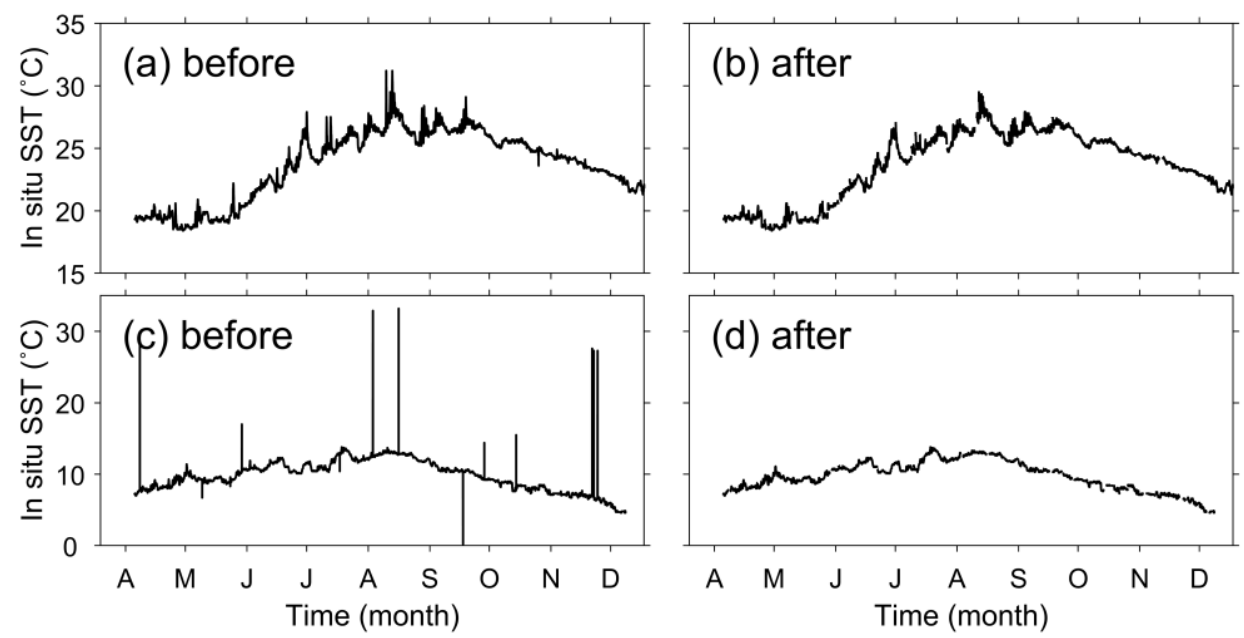

Figure 2. An example of time series of in-situ drifter temperatures $\left({ }^{\circ} \mathrm{C}\right)$ (a) before and (b) after QC procedure to eliminate abnormal temperatures in 2011. (c,d) present another example of the QC procedure.

\subsection{Sea Surface Wind}

Wind speed is one of most essential parameters producing SST differences related to the diurnal variability of the SSTs [37,38], skin-bulk SST difference [39], and so on. In order to evaluate the errors of satellite-derived SSTs and to understand dependency on the wind field, we used the wind speed data observed by the Special Sensor Microwave Imager Sounder (SSMIS). The SSMIS wind speed data are processed and provided by Remote Sensing System (RSS) [40].

\subsection{Daily Sea Surface Temperature}

In the NLSST algorithm, Walton et al. [17] and Hosoda et al. [41] recommended climatological SST for a first-guess SST. However, climatology data should not be used as a first-guess SST in coastal areas where small-scale ocean features cause high SST variability. In order to compensate for this problem, the Operational Sea surface Temperature and sea-Ice Analysis (OSTIA) data of Met Office were acquired in order to remove the cloudy and cloud-contaminated pixels and to provide a first-guess SST in the NLSST algorithm. The OSTIA uses the optimal interpolation method to compose infrared and microwave satellite, and in situ, SST measurements [42], and provides global high-resolution $\left(1 / 20^{\circ}\right)$, gap-free SST, and sea-ice products on daily base [43,44]. 


\section{Methods}

\subsection{Removal of Cloud Contaminated and Problematic Pixels}

A cloud screening procedure is among the indispensable processes for deriving SSTs from satellite thermal infrared imagery. In order to eliminate the cloudy or cloud-contaminated pixels upon SST retrieval, we applied a sequence of threshold tests based on the differences in radiation between sea surface and clouds according to their physical properties, as shown in Table $2[45,46]$.

Table 2. List of criteria and thresholds for the removal of cloudy and cloud-contaminated pixels and pixels with inappropriate satellite zenith angle and sun reflection angle (VIS: Albedo of visible channel, $\mathrm{BT}_{\mathrm{IR} 1}$ : Brightness temperature of IR1 channel, $\mathrm{BT}_{\mathrm{IR} 2}$ : Brightness temperature of IR2 channel,

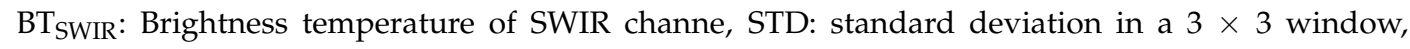
Max: maximum value in a $3 \times 3$ windo, Min: minimum value in a $3 \times 3$ window, Max. $\mathrm{BT}_{\mathrm{IR} 1}$ for 10 day: maximum value of 10 consecutive days, SZA: satellite zenith angle, SRA: solar reflection angle, SST: retrieved SST, FGSST: first-guess SST).

\begin{tabular}{|c|c|c|}
\hline \multirow{2}{*}{ Criteria } & \multicolumn{2}{|c|}{ Thresholds } \\
\hline & Day & Night \\
\hline VIS & $>5 \%$ & - \\
\hline $\mathrm{BT}_{\mathrm{IR} 1}$ & $<-3.5^{\circ} \mathrm{C}$ & $<-3.5^{\circ} \mathrm{C}$ \\
\hline STD VIS & $>0.5 \%$ & - \\
\hline $\mathrm{STD} \mathrm{BT}_{\mathrm{IR} 1}$ & $>0.7^{\circ} \mathrm{C}$ & $>0.5^{\circ} \mathrm{C}$ \\
\hline $\mathrm{STD} \mathrm{BT}_{\mathrm{IR} 2}$ & $>0.7^{\circ} \mathrm{C}$ & $>0.5^{\circ} \mathrm{C}$ \\
\hline Max. VIS-Min. VIS & $>3 \%$ & - \\
\hline Max. $\mathrm{BT}_{\mathrm{IR} 1}-\mathrm{Min} . \mathrm{BT}_{\mathrm{IR} 1}$ & $>0.7^{\circ} \mathrm{C}$ & $>0.5^{\circ} \mathrm{C}$ \\
\hline Max. $\mathrm{BT}_{\mathrm{IR} 2}-$ Min. $\mathrm{BT}_{\mathrm{IR} 2}$ & $>0.7^{\circ} \mathrm{C}$ & $>0.5^{\circ} \mathrm{C}$ \\
\hline $\mathrm{BT}_{\mathrm{IR} 1}-\mathrm{BT}_{\mathrm{IR} 2}$ & $\begin{array}{l}>0.0032 * \mathrm{BT}_{\mathrm{IR} 1}{ }^{2}+0.0996 * \mathrm{BT}_{\mathrm{IR} 1}- \\
>6^{\circ} \mathrm{C}\left(\text { if } \mathrm{BT}_{\mathrm{IR} 1}>20^{\circ} \mathrm{C}\right)\end{array}$ & $+1.607\left({ }^{\circ} \mathrm{C}\right)\left(\right.$ if $\left.\mathrm{BT}_{\mathrm{IR} 1} \leq 20^{\circ} \mathrm{C}\right)$ \\
\hline $\mathrm{BT}_{\mathrm{SWIR}}-\mathrm{BT}_{\mathrm{IR} 2}$ & - & $<\exp \left(-9.375+0.0342 * \mathrm{BT}_{\mathrm{IR} 1}\right)\left({ }^{\circ} \mathrm{C}\right)$ \\
\hline $\mathrm{BT}_{\mathrm{IR} 1}-\mathrm{Max} . \mathrm{BT}_{\mathrm{IR} 1}$ for 10 day & $<-3{ }^{\circ} \mathrm{C}$ & $<-3{ }^{\circ} \mathrm{C}$ \\
\hline SZA & $>60^{\circ}$ & $>60^{\circ}$ \\
\hline SRA & $<15^{\circ}$ & - \\
\hline | SST-FGSST | & $>3{ }^{\circ} \mathrm{C}$ & $>3{ }^{\circ} \mathrm{C}$ \\
\hline
\end{tabular}

In general, clouds are characterized by a broad, higher reflectance and lower temperature than the sea surface. The reflectance threshold test assumes that pixels with albedo exceeding $5 \%$, as measured by the VIS channel data during daytime, are cloud-contaminated. A pixel with IR1 channel BT below $-3.5^{\circ} \mathrm{C}$ was also eliminated for both daytime and nighttime in the gross cloud test. In the uniformity test, if the standard deviation or difference between the maximum and minimum of the both albedos and BTs within a window with $3 \times 3$ pixels was above each threshold, that pixel was identified as cloud. Subsequently, an additional test for a thin cirrus was performed by giving dynamic thresholds as a function of the BT of IR1 [47]. Although the VIS channel could not be utilized in the nighttime, a pixel considered as low stratus cloud was neglected using the BT difference between the SWIR and the IR2 channels. The threshold was determined depending on the BT of the IR1 channel [46]. The BT of the IR1 channel was compared with the maximum BT of IR1 channel for the previous 10 days to consider the difference in the temporal variation, as well as the spatial characteristics of the cloud and sea surface. Finally, we derived the SST fields and then compared them with the first-guess SSTs [48]. The pixels with obvious differences were contaminated by residual clouds. In addition to the cloud removal scheme, pixels with a sun glint angle of less than $15^{\circ}$ and a satellite zenith angle (SZA) larger than $60^{\circ}$ were removed from the matchup database to eliminate potential errors [13,49]. 


\subsection{Sea Surface Temperature Retrieval Equations}

The MCSST [15] and NLSST [16,17] algorithms, which are subdivided into various formulas, have been operationally used in the estimation of SST and understanding diverse oceanic phenomena, and used as input data in the numerical weather prediction models, as shown in Table 3. The NLSST equations are somewhat different in terms of the consideration of satellite zenith angle and the first-guess SST as suggested by ACSPO (Advanced Clear Sky Processor for Ocean) [50], NAVO (Naval Oceanographic Office) [51], Pathfinder [18], NRL (Naval Research Laboratory) [52], and OSI SAF (Ocean and Sea Ice Satellite Application Facility) [20,53]. One study to evaluate the performance of existing SST algorithms pointed out that the NLSST algorithm of OSI SAF was better than the other algorithms in the estimation of SST for Visible Infrared Imaging Radiometer Suite (VIIRS) data on board the Suomi National Polar-Orbiting Partnership (Suomi-NPP) [22].

Table 3. Formula based on MCSST and NLSST algorithms $\left(B T_{3.7}, B T_{11}\right.$, and $B T_{12}$ : Brightness temperature at $3.7 \mu \mathrm{m}$ (SWIR), $11 \mu \mathrm{m}$ (IR1), and $12 \mu \mathrm{m}$ (IR2), $S S T_{F G}$ : first-guess SST (in Celsius), $S_{\theta}=\sec (\theta)-1, \theta$ : satellite zenith angle, $a_{0}, a_{1}, a_{2}$, and $a_{3}$ : regression coefficients).

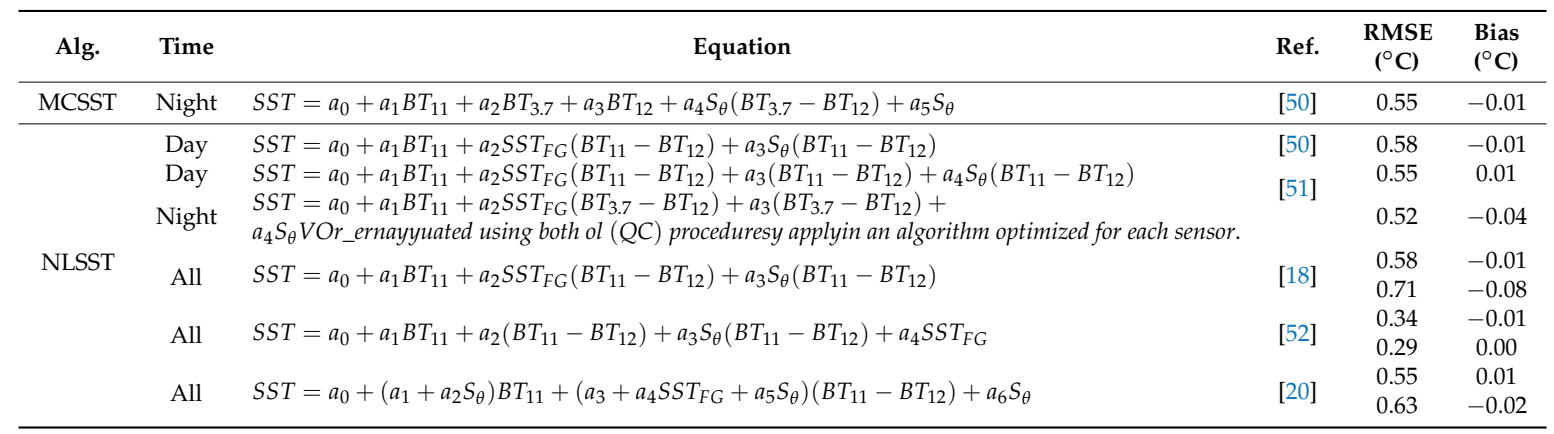

However, the following equations of MCSST and NLSST, Equations (1)-(4), have been widely used for over the past decades. Considering many aspects, we selected the algorithms in this study. In order to suggest the SST coefficients of the COMS/MI, we selected the NLSST formulation of OSI SAF to test its performance capability by the comparison with the Equations (1) and (2), as follows:

$$
\begin{gathered}
M_{C S S T} \text { split }=a_{0}+a_{1} B T_{I R 1}+a_{2}\left(B T_{I R 1}-B T_{I R 2}\right)+a_{3}\left(B T_{I R 1}-B T_{I R 2}\right)(\sec \theta-1) \\
N_{L S S T} T_{\text {split }}=a_{0}+a_{1} B T_{I R 1}+a_{2} S S T_{F G}\left(B T_{I R 1}-B T_{I R 2}\right)+a_{3}\left(B T_{I R 1}-B T_{I R 2}\right)(\sec \theta-1) \\
M_{C S S T} T_{\text {Triple }}=a_{0}+a_{1} B T_{I R 1}+a_{2}\left(B T_{S W I R}-B T_{I R 2}\right)+a_{3}\left(B T_{S W I R}-B T_{I R 2}\right)(\sec \theta-1) \\
N L S S T_{\text {Triple }}=a_{0}+a_{1} B T_{I R 1}+a_{2} S S T_{F G}\left(B T_{S W I R}-B T_{I R 2}\right)+a_{3}\left(B T_{S W I R}-B T_{I R 2}\right)(\sec \theta-1)
\end{gathered}
$$

where $B T_{S W I R}, B T_{I R 1}$, and $B T_{I R 2}$ are $B T$ measured by COMS/MI SWIR, IR1, and IR2 channel, respectively; $S S T_{F G}$ is a first-guess SST; and $\theta$ is the SZA; $a_{0}, a_{1}, a_{2}$, and $a_{3}$ are coefficients estimated by the regression scheme with in situ measurements. Equations (3) and (4) represent the MCSST and NLSST equations based on the triple windows using IR1, IR2, and SWIR bands. The MCSSTs and NLSSTs of COMS/MI data were estimated in the daytime (solar zenith angle $\leq 80^{\circ}$ ) and nighttime ( solar zenith angle $>80^{\circ}$ ) under good satellite-sun geometry conditions.

\subsection{Collocation Procedure and Validation}

In order to determine SST retrieval coefficients and validate the estimated SST fields, we generated a matchup database between the satellite observation data and in situ measurements. To constrain the errors introduced by the temporal and spatial separation, the maximum temporal interval and spatial distance between satellite-derived SSTs and in situ temperatures were set at $30 \mathrm{~min}$ and $4 \mathrm{~km}$, respectively. For screening cloudy and problematic pixels and analyzing error characteristics of SST 
retrievals, the matchup database consisted of the standard deviation and maximum difference within a $3 \times 3$ window, the SZA, solar reflection angle, and wind speed of SSMIs, as well as satellite-observed BT and in situ SST measurements.

The collocation procedure was performed to generate a 4-year matchup database between COMS data and drifter data from April 2011 to March 2015. The data for the first three years from the beginning of the data (from April 2011 to March 2014) were used to derive the SST coefficients of each algorithm in Table 3. The derived SST coefficients were applied to estimate and validate SSTs for the period of a year from April 2014 to March 2015.

\subsection{Regression Method}

SST coefficients are generally derived by applying linear least squares regression that minimizes the sum of square errors of the satellite-derived SSTs from the in situ temperatures. However, if the sub-pixel clouds that survived in the cloud detection process are present in the matchup database or if the outliers of in situ temperatures remain due to an incomplete QC process, then the linear least square method may be less accurate for estimating the SST coefficients [18]. The present regression, on the other hand, has a relatively low sensitivity to outliers compared to least square regression. Thus, the coefficients of MCSST and NLSST were derived by the robust regression between the BTs of COMS/MI and in situ temperatures.

For robust regression, the M-estimator is defined by minimizing the following function to obtain robust estimates of $\beta$ [54-56]:

$$
\beta=\operatorname{argmin} \sum_{i=1}^{n} \rho\left(\frac{\epsilon_{i}}{\tau}\right)
$$

where the $\epsilon_{i}$ is the $i$-th residual of the regression; $\tau$ is a scale factor; $\rho(\cdot)$ is related to the maximum likelihood function. Assuming the derivative of $\rho$ with respect to $\beta$ is $\psi(\cdot)$, then the robust estimator $\beta$ can be obtained by solving as follow:

$$
\sum_{i=1}^{n} x_{i} \psi\left(\frac{\epsilon_{i}}{\tau}\right)=0
$$

where $x_{\mathrm{i}}$ is satellite-observed temperature and detailed derivations are in [54-56]. To facilitate solving this equation easily, $\psi$ should be replaced to weighting function such that:

$$
w_{i}=\frac{\psi\left(\epsilon_{i} / \tau\right)}{\epsilon_{i} / \tau}
$$

It is not possible to obtain the solution directly, because the weighting function depends on the residuals of the regression. Therefore, the method of iteratively reweighted least squares is generally used until a stopping criterion is met. In this study, the coefficients for SST retrieval were determined by applying this method, which is the most common method in robust regression [57-59] with bisquare weighting functions.

\section{Results}

\subsection{Characteristics of the Matchup Database}

A total number of 284,175 matchups between the COMS/MI and in situ measurements were obtained from April 2011 to March 2015. Figure 3a shows the spatial distribution of the number of matchup points in a bin of $2^{\circ} \times 2^{\circ}$. The matchup data covers the entire COMS/MI domain, but the spatial density distribution of matchup points was not uniform. For example, in the Philippine Sea and the northwestern region of Australia, there are more than 1000 matchup points in a bin, whereas there were few or no matchups in the tropical ocean. The spatial distribution of the matchup data was affected by the topography, the presence of clouds, and the distribution of currents. 

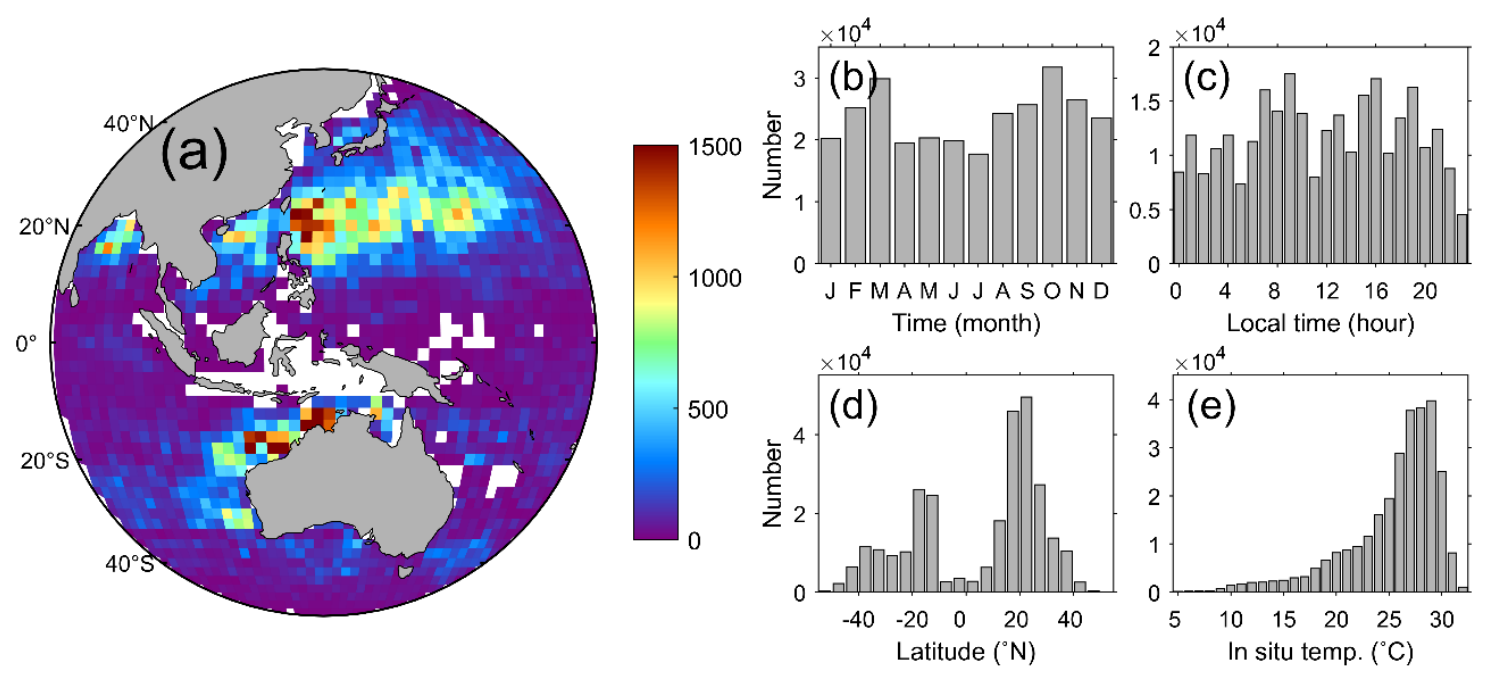

Figure 3. (a) Spatial distribution of the number of matchup points between COMS and in situ measurements in bins of $2^{\circ} \times 2^{\circ}$ and the histograms of the matchups with respect to (b) month, (c) local time (hour), (d) latitude $\left({ }^{\circ} \mathrm{N}\right)$, and (e) in situ temperature $\left({ }^{\circ} \mathrm{C}\right)$ for the period from April 2011 to March 2015.

The monthly characteristics of the number of matchup points were the lowest in July, with 17,717 and the highest in October, with 31,692 (Figure 3b). For local time, more than 7000 matchup points were generated per hour except at $23 \mathrm{~h}$ (Figure 3c). The latitudinal distribution of matchups is shown in Figure $3 \mathrm{~d}$. The latitudes of the matchups were mostly distributed between $15^{\circ} \mathrm{N}$ and $30^{\circ} \mathrm{N}$ in the Northern Hemisphere and between $10^{\circ} \mathrm{S}$ and $20^{\circ} \mathrm{S}$ in the Southern Hemisphere. However, matchups were rarely produced in the equatorial region and in the high latitudes above $40^{\circ}$. The in situ temperatures of the matchup database were in the range of $-0.2^{\circ} \mathrm{C}$ to $33.8^{\circ} \mathrm{C}$, and the number of matchups showed the maximum value between $28.5^{\circ} \mathrm{C}$ and $29.5^{\circ} \mathrm{C}$, as shown in Figure 3e.

\subsection{SST Coefficients of COMS/MI}

Figure 4 shows the differences between the estimated SST and in situ SST as a function of in situ SST for the algorithms of OSI SAF and the present study for daytime and nighttime data. One of significant features of the present formulations can be found at low range of SST, especially of less than $10^{\circ} \mathrm{C}$. As mentioned earlier in Figure $4 \mathrm{a}, \mathrm{b}$, the OSI SAF algorithms resulted in high overestimation of low SSTs. Although this might be related to the unequal distribution of matchup data that are concentrated around $30^{\circ} \mathrm{C}$ as shown in Figures 3 and 4, the overestimation should be reduced though the selection of regionally appropriate formulation. By contrast, the MCSST and NLSST formulation of this study do not reveal such significant overestimation problems at low SST range (Figure $4 \mathrm{~d}-\mathrm{f}$ ). Regardless of daytime and nighttime, MCSSTs showed near-zero bias in most range of in situ temperature ranges (Figure 4c,d). This implies that the present MCSST algorithm can contribute to solving the trend of overestimation at low temperature range.

In case of NLSST as shown in Figure 4e,f, there were slight overestimations at low temperature range $\left(<10^{\circ} \mathrm{C}\right)$ because very cold and dry atmospheric conditions were not sufficiently reflected in the estimation of coefficients. The other capability of NLSST algorithm can be detected from the errors with insignificant biases at high temperature ranges of greater than $25^{\circ} \mathrm{C}$, which improves the slight underestimation of MCSSTs $\left(<0.2^{\circ} \mathrm{C}\right)$ as shown in Figure 4 d,f. The NLSST approaches seem to reduce the nonlinear effect of water vapor at high temperature $[17,41]$. 

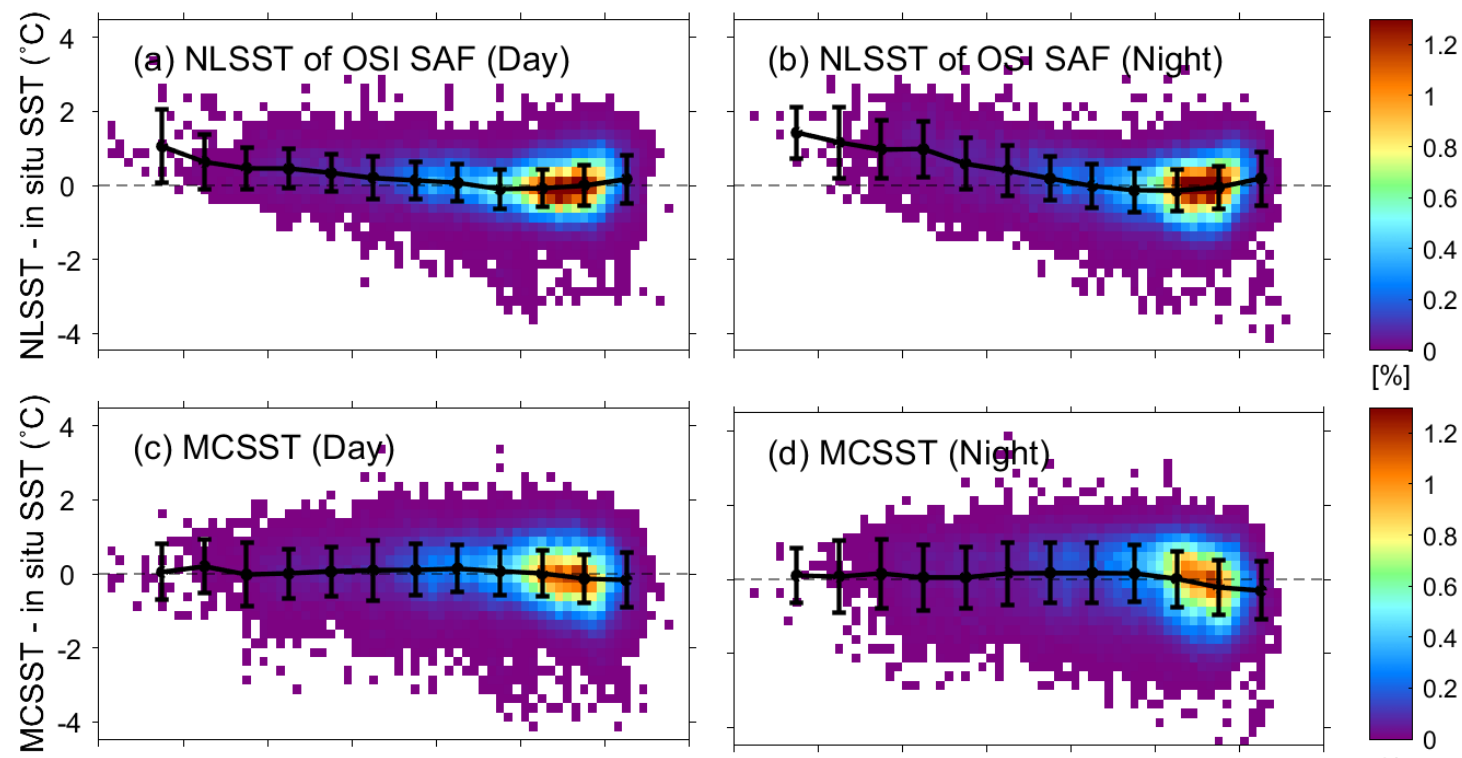

[\%]
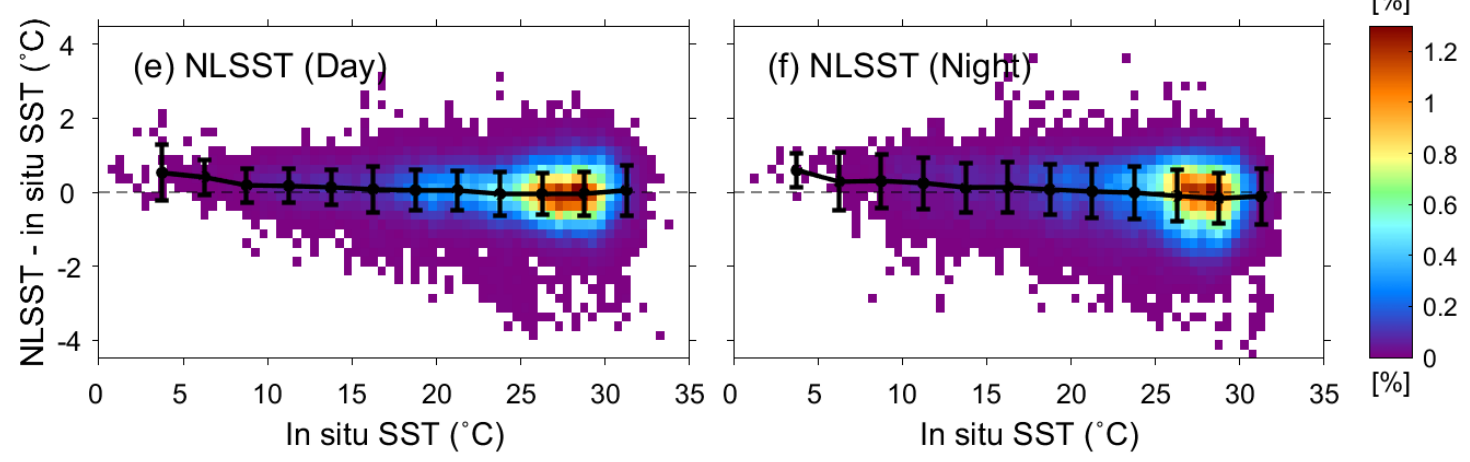

Figure 4. Distributions of NLSST errors of OSI SAF during the (a) daytime and (b) nighttime, MCSST errors during the (c) daytime and (d) nighttime, and NLSST errors in the (e) daytime and (f) nighttime as a function of the in situ SST $\left({ }^{\circ} \mathrm{C}\right)$. The color represents the percentage of the data to the total number of matchup points in each bin; error bars represent the standard deviation of SST errors of each interval.

Values in last two columns in Table 3 represent the RMSE and bias errors of the previously-known SST equations of MCSST and NLSST using the split window or the triple window. The RMSEs range from $0.29^{\circ} \mathrm{C}$ to $0.71{ }^{\circ} \mathrm{C}$ depending on algorithm and time. Although the two equations of [49] had the smallest errors, they were rejected based on the results of Petrenko et al. [22]. The MCSST and NLSST algorithms of the present study, the Equations (1) and (2), show the RMSEs of about $0.67^{\circ} \mathrm{C}$ and $0.58^{\circ} \mathrm{C}$ for daytime data and $0.79{ }^{\circ} \mathrm{C}$ and $0.71^{\circ} \mathrm{C}$ for nighttime data, respectively (Table 4). These errors are relatively high of about $0.03{ }^{\circ} \mathrm{C}$ (day) and $0.08^{\circ} \mathrm{C}$ (night) as compared with those of the algorithms in [20].

However, the estimated NLSST of OSI SAF exhibited large scatters of the differences especially at low SST range of less than about $10^{\circ} \mathrm{C}$. In addition, the NLSST errors of daytime OSI SAF presented a tendency of overestimation in that they were positive at low temperatures of about $0.5^{\circ} \mathrm{C}-1.5^{\circ} \mathrm{C}$ as shown in the Figure 4a. Such overestimation of SST seem to be amplified as the water temperature decreases from $15^{\circ} \mathrm{C}$ to $5^{\circ} \mathrm{C}$. The estimated OSI SAF NLSSTs exhibited much more positive RMS errors in the nighttime, amounting to $1.8^{\circ} \mathrm{C}$ at a range of low SST about $5^{\circ} \mathrm{C}$, than those in the daytime. 
Table 4. Coefficients of MCSST and NLSST algorithms in the Equations (1)-(4) and root mean squared errors (RMSEs) and bias errors.

\begin{tabular}{ccccccccc}
\hline \multirow{2}{*}{ Algorithm } & \multirow{2}{*}{ Type } & \multirow{2}{*}{ Time } & \multicolumn{4}{c}{ Coefficients } & \multirow{2}{*}{ RMSE $\left({ }^{\circ} \mathbf{C}\right)$} & \multirow{2}{*}{ Bias $\left({ }^{\circ} \mathbf{C}\right)$} \\
\cline { 4 - 7 } & & & $\mathbf{a 0}$ & $\mathbf{a 1}$ & $\mathbf{a 2}$ & $\mathbf{a 3}$ & & \\
\hline \multirow{3}{*}{ MCSST } & Split & Day & -0.4907 & 1.0039 & 1.9956 & 0.7340 & 0.67 & -0.02 \\
& Split & Night & 0.6351 & 1.0196 & 1.5888 & 0.7250 & 0.79 & -0.04 \\
& Triple & Night & 2.0183 & 0.9849 & 0.7737 & 0.4149 & 0.56 & -0.02 \\
\hline \multirow{3}{*}{ NLSST } & Split & Day & 2.1785 & 0.9071 & 0.0650 & 0.7499 & 0.58 & -0.01 \\
& Split & Night & 2.7423 & 0.9272 & 0.0563 & 0.6946 & 0.71 & -0.08 \\
& Triple & Night & 3.2185 & 0.9381 & 0.0259 & 0.4450 & 0.52 & -0.04 \\
\hline
\end{tabular}

Since the SSTs are extremely low of less than $0{ }^{\circ} \mathrm{C}$ in seas around the Korean Peninsula, especially in the northern part of the East Sea (called Sea of Japan), the Bohai Sea, the eastern part of the Yellow Sea off North Korea, the overestimation of SSTs at low temperature range may bring significant errors in the atmospheric and oceanic applications as well as in the potential use of weather forecast. With a viewpoint of local or regional use of the SST product, the last formulation in Table 3 [20] is not likely to be appropriate for the seas around the Korea. Thus, in this study, we adapted the general MCSST and NLSST algorithms to estimate the SST coefficients for the COMS/MI (Table 4), analyzed the error characteristics of COMS/MI-derived SSTs and validated the accuracy of these SSTs.

\subsection{Accuracy of COMS/MI SST and Spatial Distribution of Errors}

The MCSSTs and NLSSTs during the daytime and nighttime were compared with the in situ SSTs of a drifting buoy for a period of 3 years, i.e., from April 2011 to March 2014 (Figure 5). Both MCSSTs and NLSSTs showed good agreement with the in situ SSTs, with correlation coefficients of more than 0.98. Relative to the in situ SSTs, the MCSSTs had a very small negative bias of $-0.02{ }^{\circ} \mathrm{C}$ and $-0.04{ }^{\circ} \mathrm{C}$ in the daytime and nighttime respectively. The NLSSTs in both the daytime and nighttime were also slightly lower than the in situ temperatures, with a bias of $-0.01{ }^{\circ} \mathrm{C}$ and $-0.08{ }^{\circ} \mathrm{C}$, respectively. This could be due to the effect of undetected high cirrus, as well as sub-pixel clouds and abnormal atmospheric conditions [60]. The RMSEs of the NLSSTs $\left(0.58^{\circ} \mathrm{C}\right.$ in the daytime and $0.71{ }^{\circ} \mathrm{C}$ in the nighttime) were smaller than those of the MCSSTs $\left(0.67^{\circ} \mathrm{C}\right.$ during the daytime and $0.79{ }^{\circ} \mathrm{C}$ during the nighttime), which agrees with results in previous studies $[17,61]$. The accuracy of SST derived from this study is similar to that of GOES of NOAA and MTSAT (Multifunctional Transport Satellites) of JMA $[7,62]$.

Figure 6 illustrates the spatial distribution of differences between satellite-derived SSTs (MCSST and NLSST) and in situ temperatures for $5^{\circ} \times 5^{\circ}$ bin for daytime and nighttime. In some of the tropical regions, the mean bias was not calculated due to persistent cloud cover. Overall, there are biases within $\pm 0.5^{\circ} \mathrm{C}$ throughout the full-disk area except where negative biases exceeding $-0.5^{\circ} \mathrm{C}$ are identified at low latitudes. The satellite-derived SSTs tend to be overestimated in the seas around Australia. On the other hand, there is a small bias in the Northwest Pacific. The spatial pattern of mean bias is similar between MCSST and NLSST; NLSST (Figure $6 \mathrm{c}, \mathrm{d}$ ) has a smaller and uniform bias than MCSST (Figure 6a,b) during both the daytime and nighttime. 

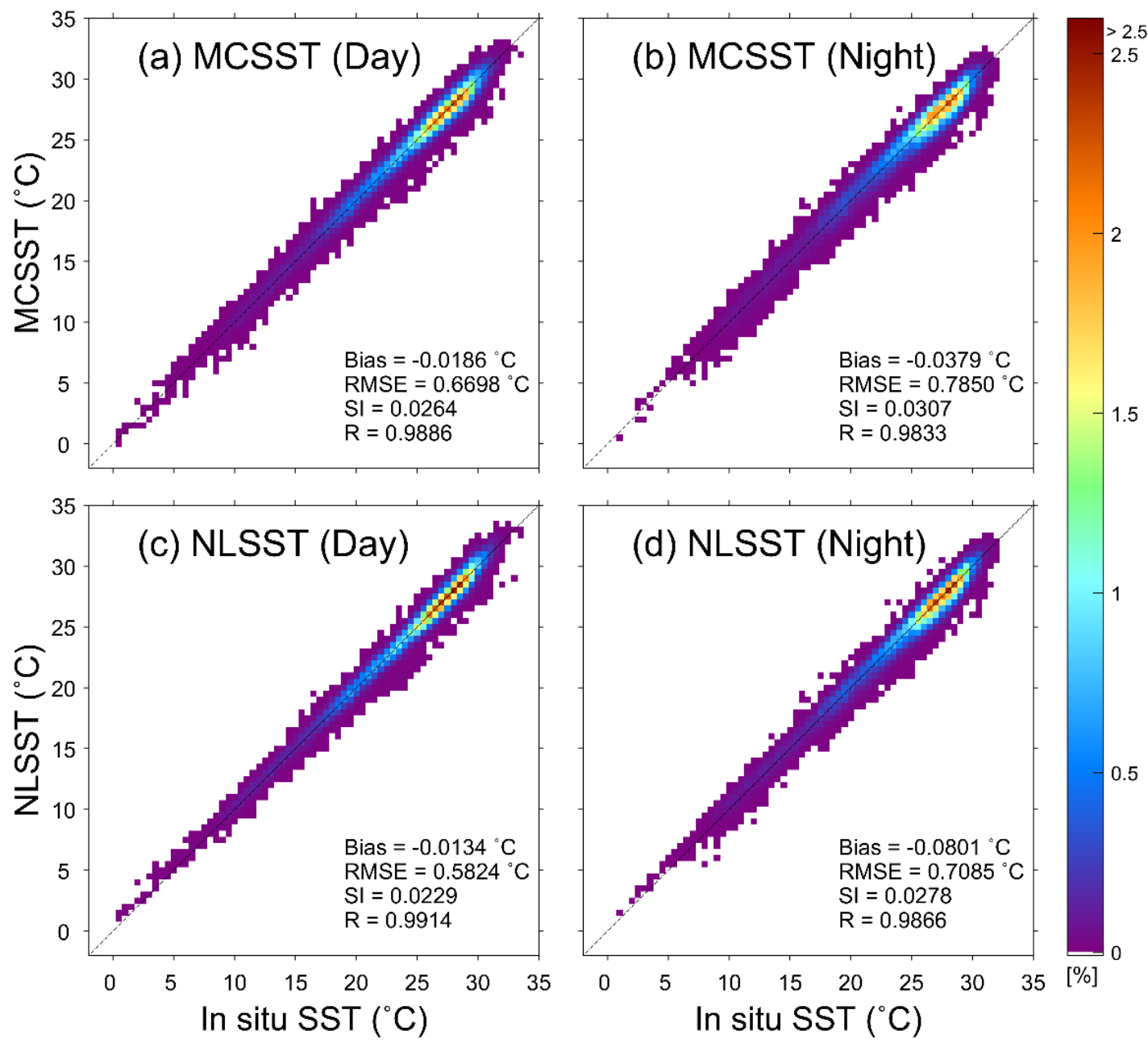

Figure 5. Comparison between MCSSTs and in situ temperatures during the (a) daytime and (b) nighttime and between NLSSTs and in situ temperatures at (c) daytime and (d) nighttime, where the color represents the percentage of the data to the total number of matchup points in a bin of $0.5 \times 0.5^{\circ} \mathrm{C}$. Bias, root mean square error (RMSE), scatter index (SI), and correlation coefficient (R) are given in each plot.

\subsection{Characteristics of Sea Surface Temperature Errors}

\subsubsection{Dependence of SST Errors on Wind Speed}

The vertical structure of water temperature in the upper ocean is affected by solar radiation, wind speed, ocean current system, and other variables. Especially under low wind speeds and high insolation condition, the diurnal thermocline of the upper ocean can develop significantly $[63,64]$. The satellite infrared sensors observe the skin temperature at a depth of about $10 \mu \mathrm{m}[39,65]$, while the buoys measure the water temperature at about $1 \mathrm{~m}$ depth. Therefore, the errors of satellite-derived SSTs with respect to the buoy temperature may represent different characteristics depending on the wind speed. 

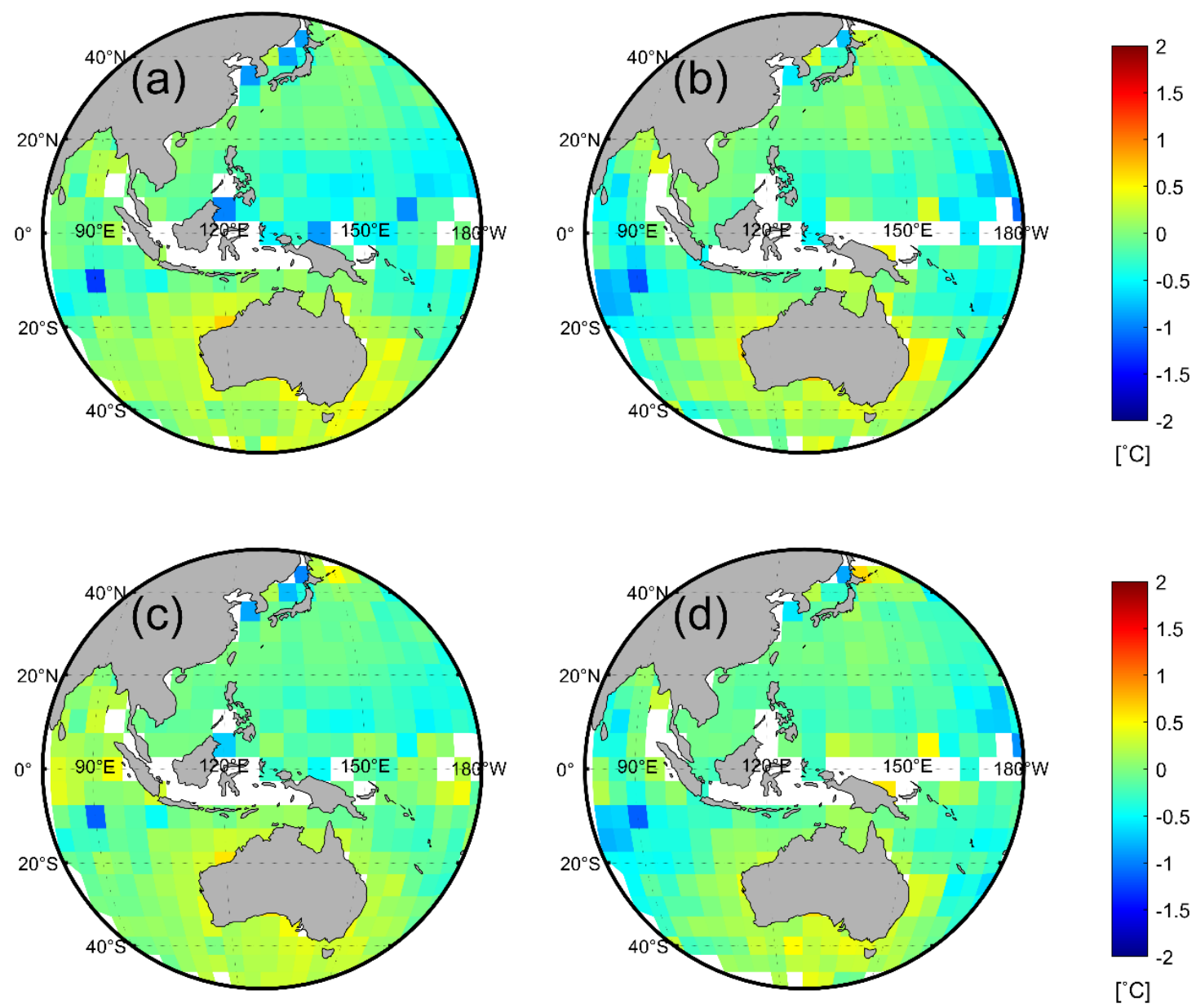

Figure 6. Spatial distribution of mean differences between MCSSTs and in situ temperatures for the

(a) daytime and (b) nighttime and between NLSSTs and in situ temperatures in the (c) daytime and

(d) nighttime in bins of $5^{\circ} \times 5^{\circ}$ for the period from April 2011 to March 2014.

In Figure 7, each panel displays a SST difference between COMS/MI and drifting buoys, as a function of wind speed from SSMIS. Both daytime and nighttime MCSST errors do not exhibit an obvious trend, as shown in Figure 7a,b. The NLSST errors also show similar characteristics to those of MCSST, with a relatively small standard deviation (Figure $6 c, d$ ). The SST calculated in this study represents the water temperature between $10 \mu \mathrm{m}$ and several tens of $\mathrm{cm}$, as coefficients were derived by applying the regression method to the drifting buoy temperature observed at about $20 \mathrm{~cm}$ depth. Strictly speaking, the SSTs derived from COMS/MI measurements in this study could not be called the skin temperature, and the drifting buoy temperatures of about $20 \mathrm{~cm}$ depth are also not a bulk temperature independent of the diurnal variations. For these reasons, the errors of COMS/MI SST in Figure 7 appear to be insensitive to wind speed, unlike the characteristics of skin-bulk temperature difference with respect to the wind speed analyzed by Donlon et al. $[43,63]$ and Minnett [64]. This implies that the present SST coefficients can be applied continuously for COMS/MI data without paying much attention to the effect of wind. 

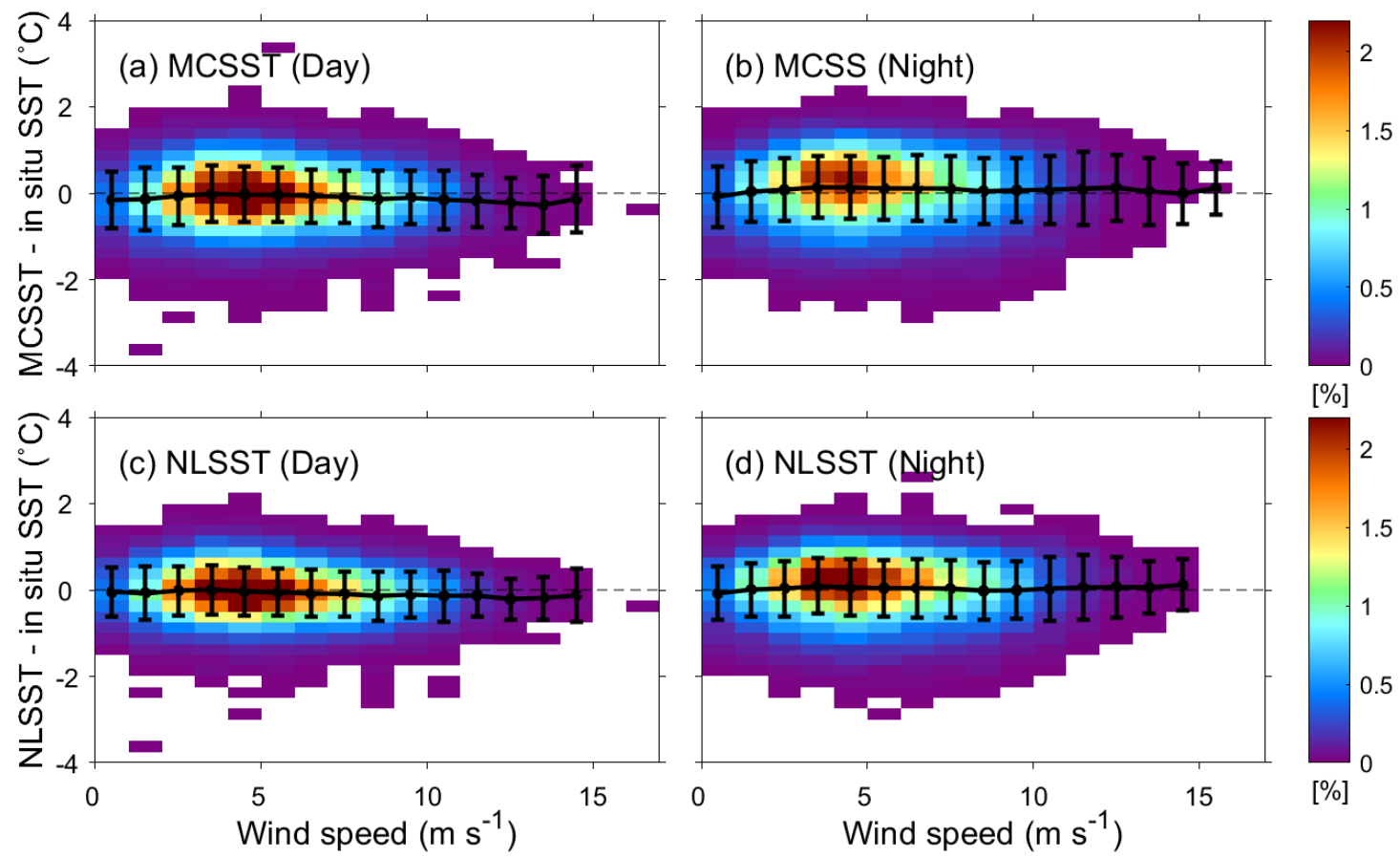

Figure 7. Distributions of SST residuals (satellite SST—in situ SST) of MCSST during the (a) daytime and (b) nighttime and NLSST during the (c) daytime and (d) nighttime as a function of wind speed $\left(\mathrm{m} \mathrm{s}^{-1}\right)$. The color represents the percentage of the data to the total number of matchup points in each bin; error bars represent the standard deviation of SST errors of each interval.

\subsubsection{Effect of Satellite Zenith Angle}

The spatial coverage of geostationary satellite images is extensive, with latitudinal and longitudinal limits of about $\pm 60^{\circ}$, and the satellite zenith angle of each pixel of COMS/MI varies over a wide range. Therefore, it is necessary to investigate if there is any influence of the SZA on the accuracy of derived SSTs. In the regression procedure, the matchup points at a high range of SZA $\left(>60^{\circ}\right)$ were removed to avoid unpredictable errors related to poor angles. Investigation of the number density of the SZA showed that the most frequent SZAs of the matchup database were mainly distributed in the range of $20^{\circ}-50^{\circ}$. At this range, there was no significant tendency in the distribution of SST biases with respect to the SZA for both MCSSTs and NLSSTs by negligible mean bias errors close to $0{ }^{\circ} \mathrm{C}$. In contrast to this, negative biases $\left(<0.3^{\circ} \mathrm{C}\right)$ were still detected at small SZA values, i.e., less than $10^{\circ}$, for both MCSSTs and NLSSTs. Considering such a small number of matchup points near the nadir, however, the overall contribution of the SZA effect on the SST errors seemed to be trivial.

The NLSST equation, containing three terms related to SZA, as shown in [20] of Table 3, did not give any limit of the SZA values in the derivation of the SST coefficients [20]. In order to examine the SZA effect on the SST accuracy of COMS/MI, the coefficients of MCSST and NLSST were preliminarily derived the entire range of SZA to estimate SSTs. Figure 8 shows the SST errors of the MCSST and the NLSST algorithms as a function of SZA. As shown in Figure $8 \mathrm{a}-\mathrm{d}$, the differences of estimated SSTs from in situ SSTs were very small at a range of $20^{\circ}-60^{\circ}$ for both nighttime and daytime data. However, the mean differences tended to be negative by up to about $-1{ }^{\circ} \mathrm{C}$ at high SZA near the outer boundary of the full-disk region [66]. 

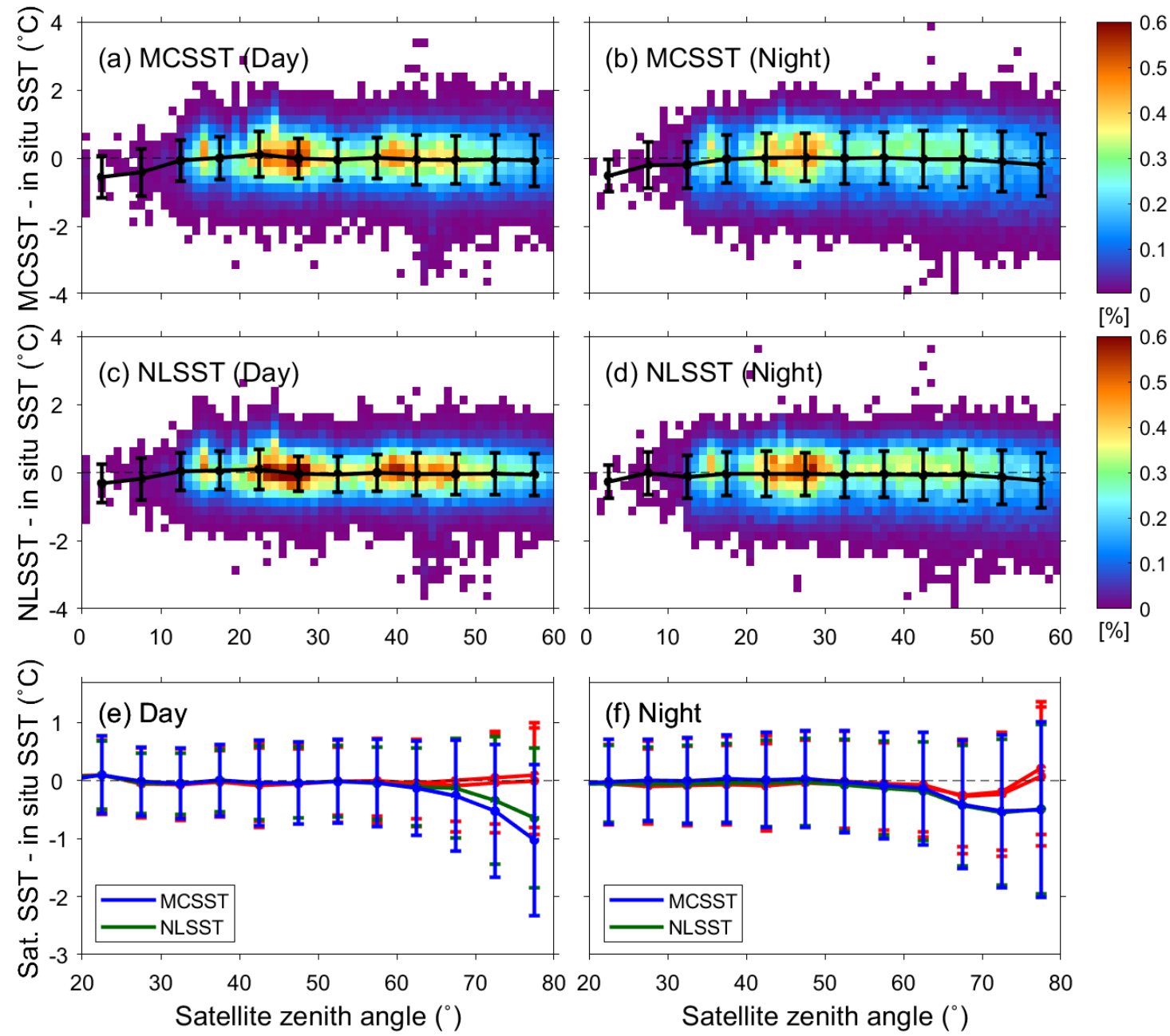

Figure 8. Distributions of MCSST errors during the (a) daytime and (b) nighttime and NLSST errors during the (c) daytime and (d) nighttime as a function of satellite zenith angle (SZA) in range of $0^{\circ}-60^{\circ}$ and mean bias and standard deviation of SST errors (blue and green) of each interval during the (e) daytime and (f) nighttime with respect to SZA in range of $20^{\circ}-80^{\circ}$, where the red bars represent SST errors in case of SZA correction term $(\sec (\theta)-1)$ included in the SST equations.

To investigate the SZA effect on the SST errors, we included all the matchups for an SZA range below than 80 in the regression procedure. Figure 8 shows the SST errors as a function of the SZA values from $20^{\circ}$ to $80^{\circ}$ for MCSST and NLSST as marked in green and blue. In the daytime, the mean errors of MCSSTs were larger than those of NLSSTs, as indicated in Figure 8e. However, the reduction effect of NLSST errors disappeared when the same errors for a range of SZA less than $60^{\circ}$ in the nighttime was shown. This implies that the present algorithms might still have SZA influences unless high SZA values, both in the matchup procedure and in the regression procedure, are removed. Therefore, it is noted that the present algorithms could be applied only for a small range of SZA $\left(<60^{\circ}\right)$ by eliminating the undesirable pixels with high SZA values to maintain SST accuracy (Table 2).

It is hypothesized that the tendency of significant underestimation at high angle limits $\left(>60^{\circ}\right) \mathrm{can}$ be reduced if the SZA term $\left(S_{\theta}=\sec (\theta)-1\right)$, as shown the last term of [20] in Table 3, was included in the regression procedure. As expected, such significant underestimation of the estimated SSTs disappeared by showing much smaller errors for MCSST and NLSST algorithms, as indicated in red lines in Figure 8e,f. However, even though the angle term was included in the SST retrieval formulations, the overestimation of SSTs still remained at high angle limits $\left(>60^{\circ}\right)$, particularly at a range of SSTs below $7^{\circ} \mathrm{C}$, as pointed out in Figure 4a,b. This proves the drawbacks of the inclusion of 
SZA term in the SST formulation by violating the hypothesis as above. Thus, the present study did not select the single term of SZA in the SST derivation equation, as shown in the Equations from (1) to (4).

\subsubsection{Latitudinal Distribution of SST Errors}

Figure 9 displays SST residuals (satellite-derived SST minus buoy SST) as a function of latitude. The mean and standard deviation of SST residuals for each 10-degree latitude bin are also illustrated as error bars. Overall, the MCSST residuals have a certain dependence on latitude (Figure 8a,b), but the NLSST residuals in Figure 9c,d do not have any dependency on latitude, especially during the nighttime. MCSST retrievals have a slightly negative bias in the tropical region, and the bias changes to positive toward higher latitudes in both the Southern and Northern Hemispheres. As can be inferred from Figure 9a, MCSSTs are higher than in situ SSTs in the Southern Hemisphere compared to the Northern Hemisphere. This might be associated with a high density of the matchups at mid-latitude regions in the Northern Hemisphere. It may be concluded that the results in Figure 9 did not reveal any characteristic distribution of the errors with regard to the latitude. This suggests that the derived coefficients can be applied to the estimation of both MCSST and NLSST without serious latitudinal dependence.
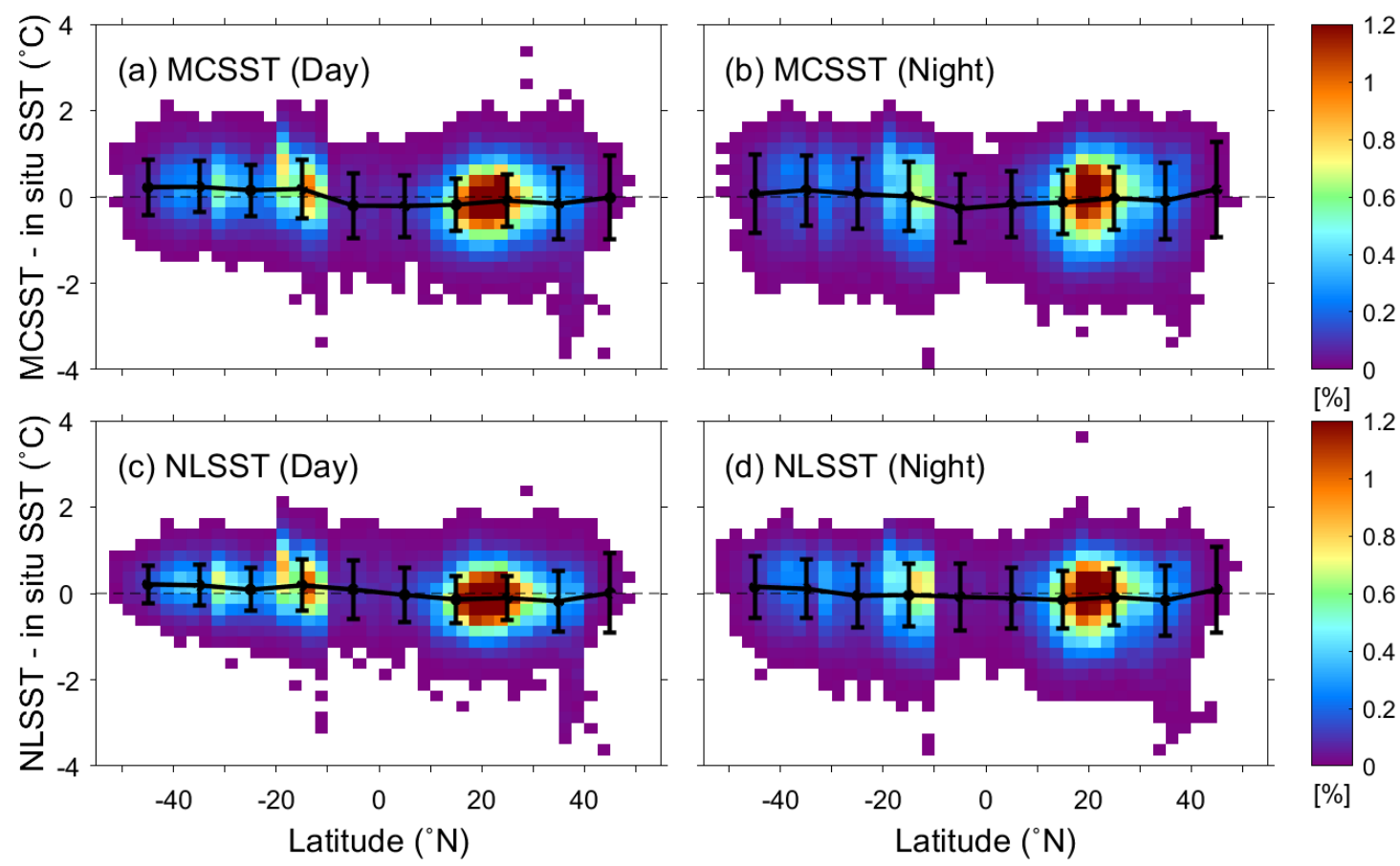

Figure 9. Distributions of MCSST errors during the (a) daytime and (b) nighttime and NLSST errors during the (c) daytime and $(\mathrm{d})$ nighttime as a function of the latitude $\left({ }^{\circ} \mathrm{N}\right)$.

\subsubsection{Coastal Effects on SST Errors}

In order to analyze the characteristics of SST errors in the coastal region, the mean biases and standard deviations of the SST residuals were investigated with respect to distance from the coast (Figure 10). The errors of COMS/MI SSTs do not show any characteristic trend at offshore regions $(>10 \mathrm{~km}$ ) for all algorithms, regardless of daytime and nighttime data (Figure 10c). However, it is noteworthy that negative biases appear in coastal regions with a distance of less than $10 \mathrm{~km}$. Moving closer to the coastline, the errors enlarge with significant negative biases $\left(<0.3^{\circ} \mathrm{C}\right)$. In coastal regions within $10 \mathrm{~km}$ from the coast, the radiance measured by COMS/MI with $4 \mathrm{~km}$ resolution at nadir is likely to include land contaminations. In addition, the characteristics of SSTs with small scale and high variability of small-scale features in the coastal region could induce the differences between the spatially-averaged SSTs of the satellite and the temperature measured by in situ temperature 
measurements $[67,68]$. Thus, the analysis of the coastal effect on SST estimation suggests that the SST derived from present algorithms should be carefully used to understand spatial and temporal variability of coastal phenomena requiring accurate SST fields.

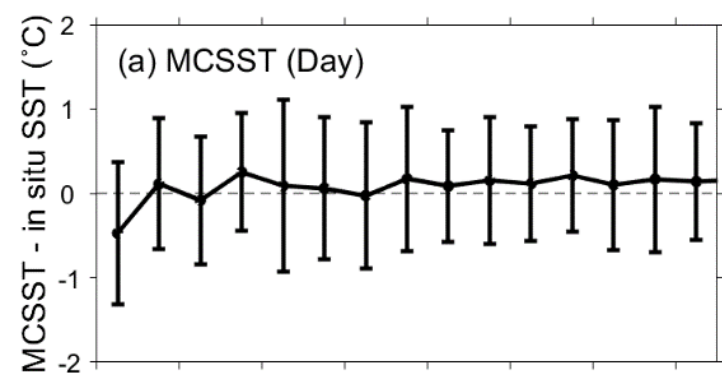

(b) MCSST (Night)

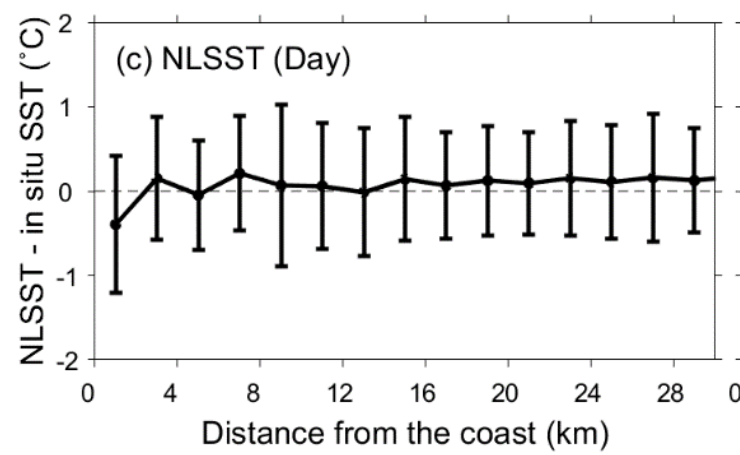

(d) NLSST (Night)

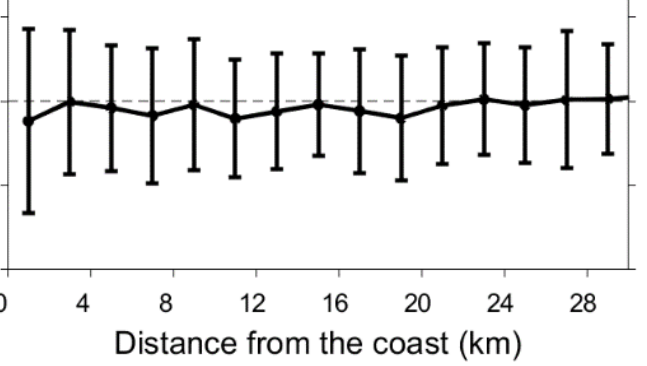

Figure 10. A plot of averaged MCSST errors during the (a) daytime and (b) nighttime and NLSST errors during the (c) daytime and (d) nighttime as a function of distance from the coast $(\mathrm{km})$. The error bars indicate the standard deviation of SST errors in each interval.

\subsection{Validation of Retrieved SST}

In order to verify that the SSTs derived from COMS/MI were stable even after the period to estimate SST coefficients, we validated the retrieved SSTs based on the in situ SSTs measured by drifting buoys from April 2014 to March 2015. As shown in Figure 11, the errors of retrieved SSTs for whole cases are quite similar to the results for 3 years from 2011 to 2014 in Figure 5. The validation results using the independent matchup points show that the RMSE and biases for retrieved MCSST (Figures 10 and 11) in the study area are, respectively, $0.65^{\circ} \mathrm{C}$ and $-0.05^{\circ} \mathrm{C}$ in daytime and $0.80{ }^{\circ} \mathrm{C}$ and $-0.09^{\circ} \mathrm{C}$ in nighttime. The NLSST (Figures 10 and 11) seems to be more accurate than MCSST, with RMSEs of $0.55^{\circ} \mathrm{C}$ in the daytime and $0.71^{\circ} \mathrm{C}$ in the nighttime. 

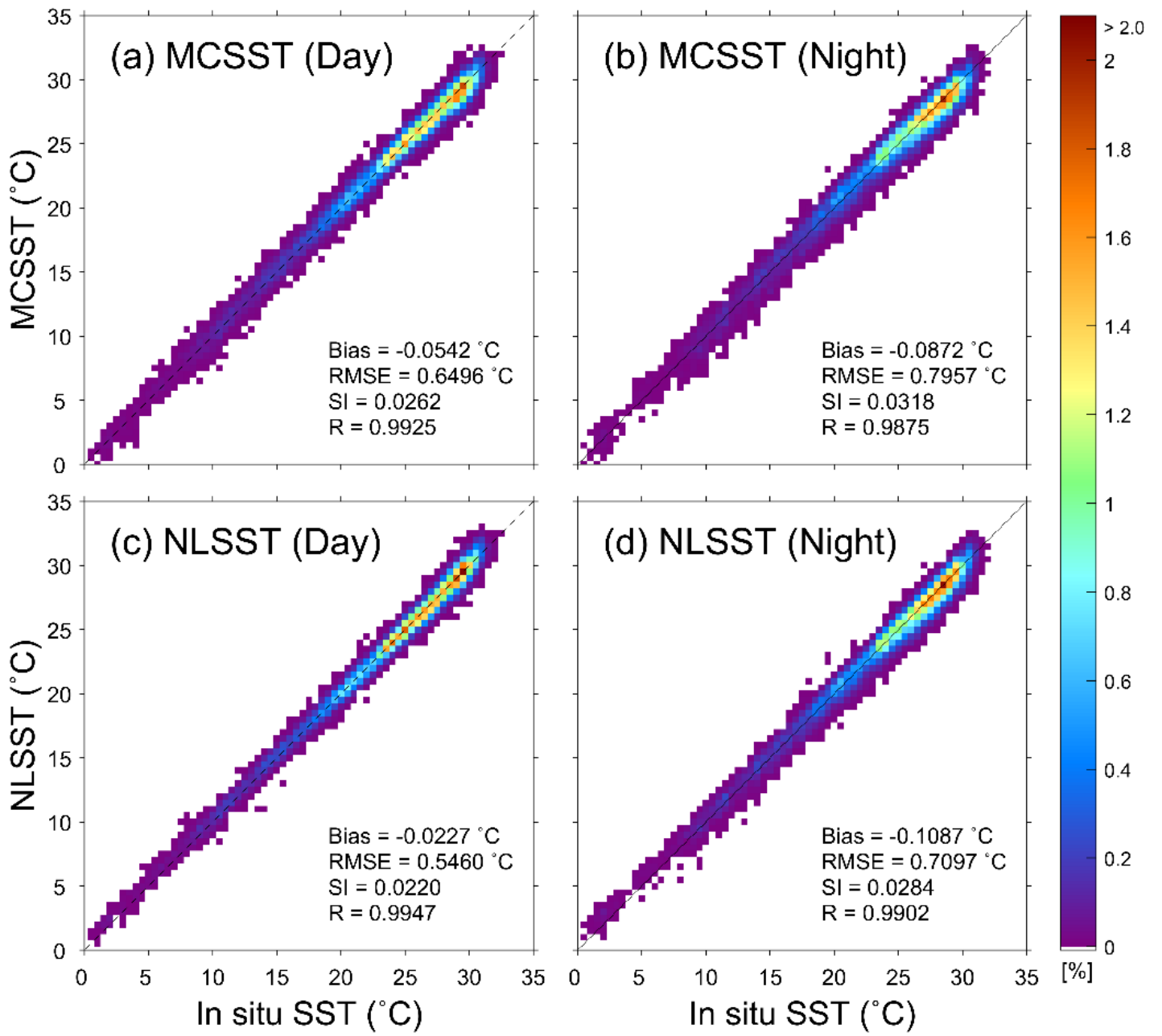

Figure 11. Comparison between MCSSTs and in situ temperatures during the (a) daytime and (b) nighttime and between NLSSTs and in situ temperatures during the (c) daytime and (d) nighttime for the period from April 2014 to March 2015, where the color represents the percentage of the data to the total number of matchup points in a bin of $0.5^{\circ} \mathrm{C} \times 0.5^{\circ} \mathrm{C}$. Bias, root mean square error (RMSE), scatter index (SI), and correlation coefficient (R) are given in each plot.

Figure 12 shows the spatial distribution of RMSEs and mean biases in $5^{\circ} \times 5^{\circ}$ bins for MCSST and NLSST from COMS/MI with respect to the buoy SST. Most of bins of MCSST errors show relatively small RMSE values, i.e., less than $0.8^{\circ} \mathrm{C}$, except for the pixels near the boundary of the full-disk region with relatively high SZA (Figure 12a). This trend was also detected in the case of NLSST; however, its amplitudes of the RMSE significantly improved by showing much lower values $\left(<0.6{ }^{\circ} \mathrm{C}\right)$ except for the boundary region of COMS/MI observation (Figure 12c). The bias errors of MCSSTs ranged from $-0.5^{\circ} \mathrm{C}$ to $0.5^{\circ} \mathrm{C}$, excluding a single bin east of Australia with a bias error of about $1.0^{\circ} \mathrm{C}$. This large error of about $1.0^{\circ} \mathrm{C}$ is presumably attributed to a significantly small number of matchups, i.e., 29 , occupying $1.1 \%$ of the maximum number of 2638 at a bin in the Northwest Pacific; therefore, it may be handled as an outlier. 

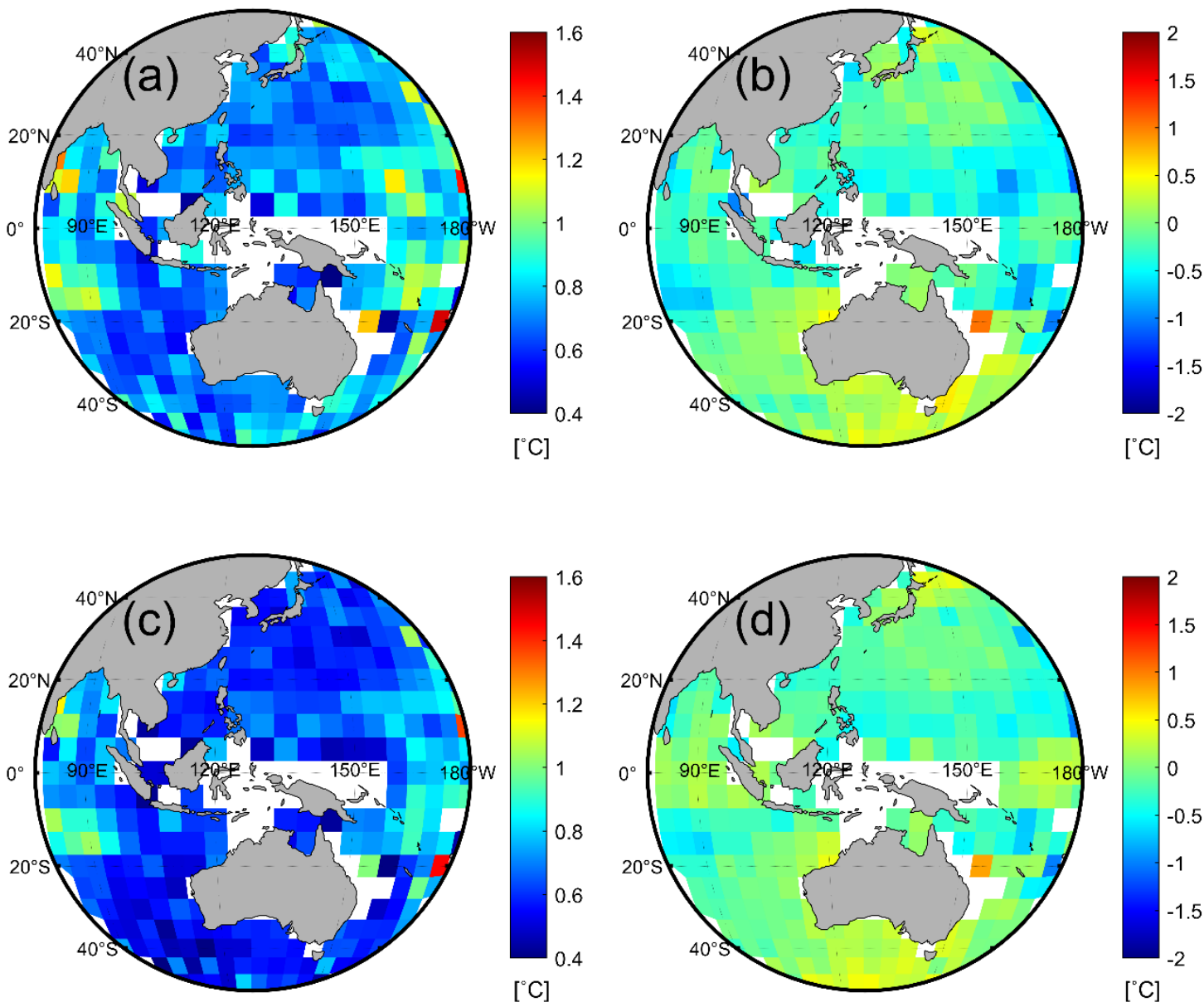

Figure 12. Spatial distribution of (a) root mean square errors (RMSEs) and (b) mean biases of MCSSTs and (c) RMSEs and (d) mean biases of NLSST from in situ temperatures in bins of $5^{\circ} \times 5^{\circ}$ for the period from April 2014 to March 2015.

As shown in Figure $12 \mathrm{~b}, \mathrm{~d}$, the spatial distribution of mean biases of NLSST with a standard deviation value of $0.27^{\circ} \mathrm{C}$ was more uniform than those of mean biases of MCSST with a value of $0.32{ }^{\circ} \mathrm{C}$. This implies that the NLSST algorithm is more effective than the MCSST algorithms for COMS data. As a result of extended validation for both algorithms, it is confirmed that the present algorithms can be operationally used for COMS/MI data.

\subsection{Comparison of Derived SSTs with Other SST Product}

In order to examine whether the derived SST coefficients can be operated properly in the entire COMS region, we estimated SSTs based on the present NLSST algorithm on 26 March 2015. Since there was considerable cloud coverage in the mid-latitude region as well as in the tropical regions, all SST images were composited to produce a daily SST field by taking the average, as shown in Figure 13a. In order to compare the satellite-derived SST with L4 SSTs, the OSTIA SST on the same date is illustrated in Figure 13b. Our overall comparison indicated that the two SST images were quite similar in terms of temperature ranges and oceanic features. For a deeper comparison, the estimated SST images were enlarged to concentrate on the seas around the Korean Peninsula, as shown in Figure 12c,d. Both SST images presented large-scale oceanic features such as the Kuroshio Current and subpolar front in the East Sea (called Sea of Japan). The COMS/MI-derived SSTs expressed small-scale features in detail, such as the fine structure of the Kuroshio meandering, and mesoscale eddies in the vicinity of the subpolar frontal region, which was in contrast to the smoothed and filtered composite SST field of OSTIA. The details of the small-scale and fast-changing features are unlikely to appear in the L4 SST 
fields due to their long repeating period (usually more than one day), as well as to the large swath gap of the polar-orbit satellite $[69,70]$.
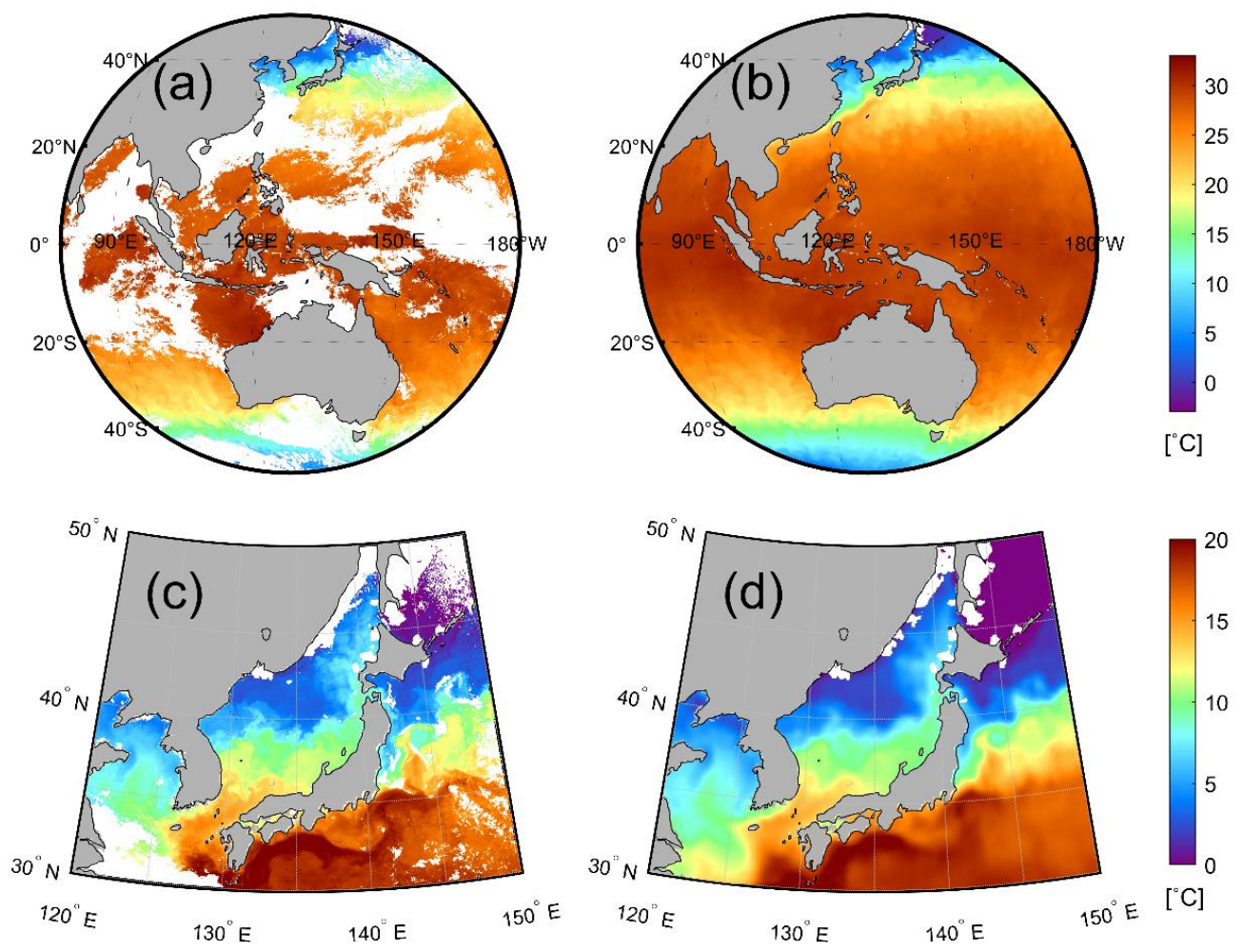

Figure 13. Example of daily SST fields $\left({ }^{\circ} \mathrm{C}\right)$ from (a) COMS/MI-derived SST and (b) OSTIA on March 26, 2015. (c,d) are SSTs in the seas around the Korean Peninsula, enlarged images from $(\mathbf{a}, \mathbf{b})$, respectively.

The OSTIA SST is one of the best SST composites; it combines all available satellite data and in situ measurements over the course of a day. However, its current product does not include any SSTs from geostationary satellite data covering this particular region. Thus, it is believed that the SST product may depend on AMSR2 SSTs from microwave remote sensing in the optimal interpolation procedure. In light of this, the present SSTs of COMS/MI, which are derived several times a day, can contribute to the capability of data sampling in the daily SST product over the full-disk region by overcoming the limitations of observations by other near-polar orbiting satellites. Eventually, the present SSTs are anticipated to be operational not only in daily SST composites, but also for diverse applications in the atmospheric and oceanic fields.

\section{Discussion}

The first Korean geostationary satellite COMS has been successfully operating since 2010. It has been operating stably, with relatively high accuracy of measured radiance to derive SST fields. Thus, the proper selection of SST retrieval equations and derivation of the SST coefficients are of importance for diverse atmospheric and oceanic applications. Concerning COMS/MI SST, this study raised the following questions: What kind of SST retrieval equations are the most appropriate for COMS data? Are there any problems associated with the use of SST formulations such as MCSST or NLSST over the COMS region? Are there any characteristic errors or regional biases in the estimation of SST? If there are significant regional biases, can be geostationary satellite SST algorithm stably used for regional seas, especially in the North Asian regions with low temperatures? To obtain potential explanations regarding such questions, we conducted the present study.

Previously well-known SST algorithms showed relatively small RMSEs and bias errors [18,20,49-51]. However, some tendencies, such as overestimation of SSTs at low temperature 
ranges were detected from the SST equations regardless variations between day and night. Since most of the matchup points are concentrated in low-latitude regions, biases can be amplified, because the characteristics of low temperature are not properly considered in the retrieval procedure of SST coefficients. This problem can be an important issue in the derivation of regional SST fields in low-temperature areas in particular.

Another issue concerns the errors of SST with respect to SZA. In order to remove the errors related to the SZA, additional terms for SZA have long been proposed in several algorithms [20,51]. However, the geostationary SST provided by the previous algorithms showed that the overestimation phenomenon appeared even though the formulation contained the SZA correction term in the SST formulations. The error characteristics of the algorithms were related to the problem of COMS/MI-derived SST at low temperatures. Therefore, we focused on the utilization of full-disk data and proposed a SST retrieval formula without the single term of SZA correction to restrain peculiar biases at a range of low temperature.

As can be seen from the results of this study, when calculating the SST using the radiance data observed from the COMS/MI, the appropriate algorithm should be decided according to the application purposes. If more accurate SST estimations from COMS/MI data are required at low temperatures, it is recommended that an equation be used that does not include the SZA correction term by removing the edges of the full-disk of COMS/MI. To understand the pattern of COMS SST for the whole area of the full-disk, one may use the calculation formula including the SZA correction term, but it is important to understand the characteristics of SST in the seas around the Korean Peninsula. Such characteristic errors of under- or over- estimation are likely to be caused by a lack of in situ measurements in the matchup database. Therefore, it is necessary to observe SSTs at high-latitude regions with low water temperatures in winter.

The geostationary satellite-based SST data are of importance for utilization in the local area at relatively high-latitude regions in the marginal seas around the Korea, as well as for large ocean-scale studies. SST estimates from geostationary satellite measurements over full-disk region may have regional biases, especially near the edge of the full-disk region and at high-latitude regions with limited sampling of low temperatures. Therefore, this study pointed out that the COMS/MI SSTs should be regionally optimized for more reliable scientific research through the process of in-depth investigation of the SST errors.

\section{Summary and Conclusions}

The COMS/MI has observed sea-surface radiances that can be used for the estimation of SST in extensive regions including the western Pacific Ocean and the eastern Indian Ocean. Its areal coverage contains most of the countries with the highest population in the world. So, the spatial and temporal variations of SSTs in the seas within the COMS coverage are of significance in many aspects. Many international institutions have been producing daily, weekly, or monthly SST products. However, the contribution of geostationary satellites in this region has been very low, except for the recent Japanese geostationary satellite, Himawari-8, with unprecedented spatial and temporal resolution. The COMS/MI data can also contribute to the composite SST product. To do so, there is a strong need for the SST coefficients to be optimized to COMS/MI observations. Unfortunately, the SST coefficients of COMS/MI over the full disk area that satisfy a certain level of accuracy have not been available. Thus, this study tried to suggest optimized algorithms and coefficients which are able to estimate the SSTs for the past years covering the entire period of COMS' operation.

Prior to the derivation of the SST coefficients of COMS/MI, a procedure of quality control was applied to surface drifting buoy data for the period of April 2011 to March 2015. In addition, a series of the threshold methods were also applied to satellite observations to remove cloud-contaminated and problematic pixels. The thresholds of each step were determined by being optimized for COMS/MI. Then, the matchup database between the COMS/MI-observed radiance data and in situ measurements were generated to estimate the coefficients for SST retrieval and to validate the accuracy 
of COMS/MI-derived SSTs. The number of matchup points generated through the quality-control procedure was ultimately 284,175 for the four years.

The RMSEs and bias errors were slightly higher than the other representative algorithm suggested by OSI SAF, addressing the effect of the satellite zenith angle in the formulation. However, the present algorithms revealed better performance at low SST range, i.e., less than $10^{\circ} \mathrm{C}$. The low SST range is of importance in the regional seas around the Korean Peninsula for which SSTs tends to decrease below $0{ }^{\circ} \mathrm{C}$ in winter, especially along the Russian coast in the East Sea (called Sea of Japan) and at a part of the Bohai Sea and coastal region of the North Korea. These regions are also very important for weather forecasts, as well as for oceanographic applications. Although the present algorithms do not eliminate the SZA effects on SST errors, especially at the edge of the full-disk region, the estimated SSTs seem to have advantages in terms of the non-existence of extreme overestimation or underestimation. The errors of COMS/MI-derived SSTs exhibited underestimation in coastal regions with a distance of less than $10 \mathrm{~km}$ from the coastline, regardless of MCSST or NLSST. This might be related to diverse causes from coastal topography, small-scale oceanic features, land contamination, and so on. It is recommended that the present coefficients should be taken into account for the determination of SSTs at particular coastal regions. SST errors did not reveal any characteristics with regard to both wind speed and latitude.

For the validation of the estimates of SST coefficients, the COMS/MI SSTs derived from April 2014 to March 2015 were compared with in situ temperatures. The validation results confirmed the possibility of the continuous use of the SST coefficients. Thus, it is expected that the COMS/MI SST data of more than 7 years, which is retrieved using the coefficients suggested in this study, can be used to understand ocean phenomena and to produce the SST climatology fields for the Asia-Pacific region.

Author Contributions: Conceptualization, K.-A.P.; Methodology, K.-A.P. and H.-J.W.; Data Processing and Validation, H.-J.W. and E.-Y.L.; Writing-Original Draft Preparation, H.-J.W.; Writing-Review, Editing \& Discussion, K.-A.P., X.L. and E.-Y.L.

Funding: This work was funded by the Korea Meteorological Administration Research and Development Program under Grant KMI2018-05110.

Acknowledgments: OSTIA SST data were provided by GHRSST, UKMO and CMEMS. SSMIS data are produced by Remote Sensing Systems. Data are available at www.remss.com/missions/ssmi.

Conflicts of Interest: The authors declare no conflict of interest.

\section{References}

1. Zhang, F.; Li, X.; Hu, J.; Sun, Z.; Zhu, J.; Liu, Z.; Chen, Z. Summertime sea surface temperature and salinity fronts in the southern Taiwan Strait. Int. J. Remote Sens. 2014, 35, 4452-4466. [CrossRef]

2. Li, X.; Donato, T.; Zheng, Q.; Pichel, W.G.; Clemente-Colon, P. An extraordinary breach of the Gulf Stream north wall by a cold water intrusion. Geophys. Res. Lett. 2002, 29. [CrossRef]

3. Li, X.; Zheng, W.; Pichel, W.G.; Zou, C.; Clemente-Colon, P.; Friedman, K.S. A cloud line over the Gulf Stream. Geophys. Res. Lett. 2004, 31, L14108. [CrossRef]

4. Kawai, Y.; Wada, A. Diurnal sea surface temperature variation and its impact on the atmosphere and ocean: A review. J. Oceanogr. 2007, 63, 721-744. [CrossRef]

5. Casey, K.S.; Cornillon, P. Global and regional sea surface temperature trends. J. Clim. 2001, 14, 3801-3818. [CrossRef]

6. Hartmann, D.L.; Klein Tank, A.M.G.; Rusticucci, M.; Alexander, L.V.; Brönnimann, S.; Charabi, Y.; Dentener, F.J.; Dlugokencky, E.J.; Easterling, D.R.; Kaplan, A.; et al. Observations: Atmosphere and surface. In Climate Change 2013: The Physical Science Basis. Contribution of Working Group I to the Fifth Assessment Report of the Intergovernmental Panel on Climate Change; Stocker, T.F., Qin, D., Plattner, G.-K., Tignor, M., Allen, S.K., Boschung, J., Nauels, A., Xia, Y., Bex, V., Midgley, P.M., Eds.; Cambridge University Press: Cambridge, UK; New York, NY, USA, 2013; pp. 1-96. 
7. Maturi, E.; Harris, A.; Mittaz, J.; Merchant, C.; Potash, B.; Meng, W.; Sapper, J. NOAA's sea surface temperature products from operational geostationary satellites. Bull. Am. Meteorol. Soc. 2008, 89, 1877-1888. [CrossRef]

8. Schmetz, J.; Pili Tjemkes, P.S.; Just, D.; Kerkmann, J.; Rota, S.; Ratier, A. An introduction to Meteosat Second Generation (MSG). Bull. Am. Meteorol. Soc. 2002, 83, 977-992. [CrossRef]

9. Bessho, K.; Date, K.; Hayashi, M.; Ikeda, A.; Imai, T.; Inoue, H.; Kumagai, Y.; Miyakawa, T.; Murata, H.; Ohno, T.; et al. An Introduction to Himawari-8/9-Japan's new-generation geostationary meteorological satellites. J. Meteorol. Soc. Jpn. 2016, 94, 151-183. [CrossRef]

10. Anding, D.; Kauth, R. Estimation of sea surface temperature from space. Remote Sens. Environ. 1970, 1, 217-220. [CrossRef]

11. Prabhakara, C.; Dalu, G.; Kunde, V.G. Estimation of sea surface temperature from remote sensing in 11 to 13 $\mu \mathrm{m}$ window region. J. Geophys. Res. 1974, 79, 5039-5044. [CrossRef]

12. McMillin, L.M. Estimation of sea surface temperature from two infrared window measurements with different absorptions. J. Geophys. Res. 1975, 80, 5113-5117. [CrossRef]

13. Bernstein, R.L. Sea surface temperature estimation using the NOAA-6 satellite Advanced Very High Resolution Radiometer. J. Geophys. Res. 1982, 87, 9455-9465. [CrossRef]

14. McMillin, L.M.; Crosby, D.S. Theory and validation of the multiple window sea surface temperature technique. J. Geophys. Res. 1984, 89, 3655-3661. [CrossRef]

15. McClain, E.P.; Pichel, W.G.; Walton, C.C. Comparative performance of Avhrr-based Multichannel Sea Surface Temperatures. J. Geophys. Res. 1985, 90, 11587-11601. [CrossRef]

16. Walton, C.C. Nonlinear multichannel algorithms for estimating sea surface temperature with AVHRR Satellite Data. J. Appl. Meteorol. 1988, 27, 115-124. [CrossRef]

17. Walton, C.C.; Pichel, W.G.; Sapper, J.F.; May, D.A. The development and operational application of nonlinear algorithms for the measurement of sea surface temperatures with the NOAA polar-orbiting environmental satellites. J. Geophys. Res. 1998, 103, 27999-28012. [CrossRef]

18. Kilpatrick, K.A.; Podestá, G.P.; Evans, R. Overview of the NOAA/NASA advanced very high resolution radiometer Pathfinder algorithm for sea surface temperature and associated matchup database. J. Gephys. Res. 2001, 106, 9179-9197. [CrossRef]

19. Li, X.; Pichel, W.; Maturi, E.; Clemente-Colón, P.; Sapper, J. Deriving the operational nonlinear multi-channel sea surface temperature algorithm coefficients for NOAA-15 AVHRR/3. Int. J. Remote Sens. 2001, 22, 699-704. [CrossRef]

20. OSI SAF. Geostationary Sea Surface Temperature Product User Manual; Technical Report; EUMETSAT: Berlin, Germany, 2011.

21. François, C.; Brisson, A.; Le Borgne, P.; Marsouin, A. Definition of a radiosounding database for sea surface brightness temperature simulations: Application to sea surface temperature retrieval algorithm determination. Remote Sens. Environ. 2002, 81, 309-326. [CrossRef]

22. Petrenko, B.; Ignatov, A.; Kihai, Y.; Stroup, J.; Dash, P. Evaluation and selection of SST regression algorithms for JPSS VIIRS. J. Geophys. Res. Atmos. 2014, 119, 4580-4599. [CrossRef]

23. Kramar, M.; Ignatov, A.; Petrenko, B.; Kihai, Y.; Dash, P. Near Real Time SST Retrievals from Himawari-8 at NOAA using ACSPO system. In Proceedings of the Ocean Sensing and Monitoring VIII, Baltimore, MD, USA, 17-21 April 2016; Arnone, R.A., Hou, W.W., Eds.; SPIE: Baltimore, MD, USA, 2016; p. 98270L. [CrossRef]

24. Liang, X.; Ignatov, A.; Kihai, Y. Implementation of the Community Radiative Transfer Model in Advanced Clear-Sky Processor for Oceans and validation against nighttime AVHRR radiances. J. Geophys. Res. 2009, 114, D06112. [CrossRef]

25. Dash, P.; Ignatov, A. Validation of clear-sky radiances over oceans simulated with MODTRAN4. 2 and global NCEP GDAS fields against nighttime NOAA15-18 and MetOp-A AVHRR data. Remote Sens. Environ. 2008, 112, 3012-3029. [CrossRef]

26. Merchant, C.J.; Le Borgne, P.; Marsouin, A.; Roquet, H. Optimal estimation of sea surface temperature from split-window observations. Remote Sens. Environ. 2008, 112, 2469-2484. [CrossRef]

27. Kurihara, Y.; Murakami, H.; Kachi, M. Sea surface temperature from the new Japanese geostationary meteorological Himawari-8 satellite. Geophys. Res. Lett. 2016, 43, 1234-1240. [CrossRef] 
28. Koner, P.K.; Harris, A.R.; Maturi, E. A physical deterministic inverse method for operational satellite remote sensing: An application for sea surface temperature retrievals. IEEE Trans. Geosci. Remote Sens. 2015, 53, 5872-5888. [CrossRef]

29. McPhaden, M.J.; Picaut, J. El Nino-Southern Oscillation displacements of the western equatorial Pacific warm pool. Science 1990, 250, 1385-1388. [CrossRef] [PubMed]

30. Qu, T. Mixed layer heat balance in the western North Pacific. J. Geophys. Res. 2003, 108, 3242. [CrossRef]

31. Kim, D.; Ahn, M.-H.; Choi, M. Inter-comparison of the infrared channels of the Meteorological Imager onboard COMS and hyperspectral IASI data. Adv. Atmos. Sci. 2015, 32, 979-990. [CrossRef]

32. Goldberg, M.; Ohring, G.; Butler, J.; Cao, C.; Datla, R.; Doelling, D.V.; Hewison, G.T.; Iacovazzi, B.; Kim, D.; Kurino, T.; et al. The global space-based inter-calibration system. Bull. Am. Meteorol. Soc. 2011, 92, 467-475. [CrossRef]

33. National Meteorological Satellite Center. Available online: http://nmsc.kma.go.kr (accessed on 8 October 2018).

34. Lumpkin, R.; Pazos, M. Measuring surface currents with SVP drifters: The instrument, its data and some results. In Lagrangian Analysis and Prediction of Coastal and Ocean Dynamics; Griffa, A., Kirwan, J.A.D., Eds.; Cambridge University Press: Cambridge, UK, 2007; pp. 39-67.

35. Xu, F.; Ignatov, A. In situ SST Quality Monitor (iQUAM). J. Atmos. Ocean. Technol. 2014, 31, $164-180$. [CrossRef]

36. O'Carroll, A.G.; Eyre, J.R.; Saunders, R.W. Three-way error analysis between AATSR, AMSR-E, and in situ sea surface temperature observations. J. Atmos. Ocean. Technol. 2008, 25, 1197-1207. [CrossRef]

37. Gentemann, C.L.; Minnett, P.J. Radiometric measurements of ocean surface thermal variability. J. Geophys. Res. 2008, 113, C08017. [CrossRef]

38. Gentemann, C.L. Three way validation of MODIS and AMSR-E sea surface temperatures. J. Geophys. Res. 2014, 119, 2583-2598. [CrossRef]

39. Donlon, C.J.; Minnett, P.J.; Gentemann, C.; Nightingale, T.J.; Barton, I.J.; Ward, B.; Murray, J. Toward improved validation of satellite sea surface skin temperature measurements for climate research. J. Clim. 2002, 15, 353-369. [CrossRef]

40. Remote Sensing Systems. Available online: http://www.remss.com (accessed on 8 October 2018).

41. Hosoda, K.; Murakami, H.; Sakaida, F.; Kawamura, H. Algorithm and validation of sea surface temperature observation using MODIS sensors aboard Terra and Aqua in the Western North Pacific. J. Oceanogr. 2007, 63, 267-280. [CrossRef]

42. Martin, M.J.; Hines, A.; Bell, M.J. Data assimilation in the FOAM operational short-range ocean forecasting system: A description of the scheme and its impact. Q. J. R. Meteorol. Soc. 2007, 133, 981-995. [CrossRef]

43. Donlon, C.J.; Martin, M.; Stark, J.; Roberts-Jones, J.; Fiedler, E.; Wimmer, W. The Operational Sea Surface Temperature and Sea Ice Analysis (OSTIA) system. Remote Sens. Environ. 2012, 116, 140-158. [CrossRef]

44. Copernicus Marine Environment Monitoring Service. Available online: http://marine.copernicus.eu (accessed on 8 October 2018).

45. Saunders, R.W.; Kriebel, K.T. An improved method for detecting clear sky and cloudy radiances from AVHRR data. Int. J. Remote Sens. 1988, 9, 123-150. [CrossRef]

46. Stowe, L.L.; McClain, E.P.; Carey, R.; Pellegrino, P.; Gutman, G.G.; Davis, P.; Long, C.; Hart, S. Global distribution of cloud cover derived from NOAA/AVHRR operational satellite data. Adv. Space Res. 1991, 3, 51-54. [CrossRef]

47. Závody, A.M.; Mutlow, C.T.; Llewellyn-Jones, D.T. Cloud clearing over the ocean in the processing of data from the Along-Track Scanning Radiometer (ATSR). J. Atmos. Ocean. Technol. 2000, 17, 595-615. [CrossRef]

48. Wick, G.A.; Bates, J.J.; Scott, D.J. Satellite and skin layer effects on the accuracy of sea surface temperature measurements from the GOES satellite. J. Atmos. Ocean. Technol. 2002, 19, 1834-1848. [CrossRef]

49. Park, K.; Lee, E.; Li, X.; Chung, S.; Sohn, E.; Lee, E.; Li, X.; Chung, S.; Sohn, E. NOAA/AVHRR sea surface temperature accuracy in the East/Japan Sea. Int. J. Digit. Earth 2015, 8, 784-804. [CrossRef]

50. Petrenko, B.; Ignatov, A.; Kihai, Y.; Heidinger, A. Clear-sky mask for the advanced clear-sky processor for oceans. J. Atmos. Ocean. Technol. 2010, 27, 1609-1623. [CrossRef]

51. Cayula, J.-F.P.; May, D.A.; McKenzie, B.D.; Willis, K.D. Viirs-derived sst at the naval oceanographic office: From evaluation to operation. Ocean Sens. Monit. 2013, 8724. [CrossRef] 
52. McBride, W.; Arnone, B.A.; Cayula, J. Improvements of satellite SST retrievals at full swath. In Proceedings of the Ocean Sensing and Monitoring V, Baltimore, MD, USA, 26 April-1 May 2013; Hou, W.W., Arnone, R.A., Eds.; SPIE: Baltimore, MD, USA, 2013; p. 87240R. [CrossRef]

53. Marsouin, A.; Le Borgne, P.; Legendre, G.; Péré, S.; Roquet, H. Six years of OSI-SAF METOP-A AVHRR sea surface temperature. Remote Sens. Environ. 2015, 159, 288-306. [CrossRef]

54. Huber, P.J.S. Robust estimation of a location parameter. Ann. Math. Stat. 1964, 35, 73-101. [CrossRef]

55. Holland, P.W.; Welsch, R.E. Robust regression using iteratively reweighted least-squares. Commun. Stat. Theory Methods 1977, 6, 813-827. [CrossRef]

56. Rousseeuw, P.J.; Leroy, A.M. Robust Regression and Outlier Detection; John Wiley \& Sons, Inc.: New York, NY, USA, 1987.

57. Andersen, R. Modern Methods for Robust Regression. Quantitative Applications in the Social Sciences; Sage Publications: Los Angeles, CA, USA, 2008.

58. Wilcox, R.R. Introduction to Robust Estimation and Hypothesis Testing, 3rd ed.; Academic Press: San Diego, CA, USA, 2012.

59. Soukissian, T.H.; Karathanasi, F.E. On the use of robust regression methods in wind speed assessment. Renew. Energy 2016, 99, 1287-1298. [CrossRef]

60. Simpson, J.J.; Humphrey, C. An automated cloud screening algorithm for daytime AVHRR imagery. J. Geophys. Res. 1990, 95, 13459-13481. [CrossRef]

61. Li, X.; Pichel, W.; Clemente-Colón, P.; Krasnopolsky, V.; Sapper, J. Validation of coastal sea and lake surface temperature measurements derived from NOAA/AVHRR data. Int. J. Remote Sens. 2001, 22, 1285-1303. [CrossRef]

62. Kawamura, H.; Qin, H.; Sakaida, F.; Setiawan, R.Y. Hourly sea surface temperature retrieval using the Japanese geostationary satellite, multi-functional transport satellite (MTSAT). J. Oceanogr. 2010, 66, 61-70. [CrossRef]

63. Donlon, C.J.; Nightingale, T.J.; Sheasby, T.; Turner, J.; Robinson, I.S.; Emergy, W.J. Implications of the oceanic thermal skin temperature deviation at high wind speed. Geophys. Res. Lett. 1999, 26, 2505-2508. [CrossRef]

64. Minnett, P.J. Radiometric measurements of the sea-surface skin temperature: The competing roles of the diurnal thermocline and the cool skin. Int. J. Remote Sens. 2003, 24, 5033-5047. [CrossRef]

65. Donlon, C.; Rayner, N.; Robinson, I.; Poulter, D.J.S.; Casey, K.S.; Vazquez-Cuervo, J.; Armstrong, E.; Bingham, A.; Arino, O.; Gentemann, C.; et al. The global ocean data assimilation experiment high-resolution sea surface temperature pilot project. Bull. Am. Meteorol. Soc. 2007, 88, 1197-1213. [CrossRef]

66. Merchant, C.J.; Harris, A.R.; Roquet, H.; Le Borgne, P. Retrieval characteristics of non-linear sea surface temperature from the Advanced very High Resolution Radiometer. Geophys. Res. Lett. 2009, 36, L17604. [CrossRef]

67. Ricciardulli, L.; Wentz, L.J. Uncertainties in sea surface temperature retrievals from space: Comparison of microwave and infrared observations from TRMM. J. Geophys. Res. 2004, 109. [CrossRef]

68. Castro, S.L.; Wick, G.A.; Emery, W.J. Evaluation of the relative performance of sea surface temperature measurements from different types of drifting and moored buoys using satellite-derived reference products. J. Geophys. Res. 2012, 117. [CrossRef]

69. Reynolds, R.W.; Smith, T.M.; Liu, C.; Chelton, D.B.; Casey, K.S.; Schlax, M.G. Daily high-resolution-blended analyses for sea surface temperature. J. Clim. 2007, 20, 5473-5496. [CrossRef]

70. Reynolds, R.W.; Chelton, D.B. Comparisons of daily sea surface temperature analyses for 2007-08. J. Clim. 2010, 23, 3545-3562. [CrossRef]

(C) 2018 by the authors. Licensee MDPI, Basel, Switzerland. This article is an open access article distributed under the terms and conditions of the Creative Commons Attribution (CC BY) license (http://creativecommons.org/licenses/by/4.0/). 